\title{
REVUE BIBLIOGRAPHIQUE
}

\section{Orientation du métabolisme du rumen au moyen des additifs}

\author{
Michelle DURAND \\ I.N.R.A., Station de Recherches de Nutrition \\ Centre de Recherches Zootechniques \\ F 78350 Jouy-en-Josas
}

\begin{abstract}
Résumé
Pour valoriser les rations des ruminants, on recherche des procédés permettant de limiter les pertes d'énergie (notamment sous forme de $\mathrm{CH}_{4}$ ) et d'azote (sous forme de $\mathrm{NH}_{3}$ ) au niveau du rumen sans pour autant réduire les effets bénéfiques de la digestion nicrobienne qui sont essentiellement : la dégradation des glucides des parois et la synthèse de protéines microbiennes à partir de l'azote non protéique. Divers types d'additifs ont été proposés à cet effet. Leurs avantages et inconvénients éventuels sont revus dans cet article.

Les antibiotiques ionophores, tels que monensin et lasalocide stimulent la production de propionate (élévation du pourcentage molaire), que ce soit in vitro indépendamment du mode de culture, ou in vivo avec la majorité des régimes. Il en résulte généralement une diminution du pourcentage molaire d'acétate et de butyrate et de la formation de $\mathbf{C H}_{4}$. Ils assurent, en outre, une protection des acides aminés alimentaires : on relève in vitro et in vivo une réduction de l'ammoniogénèse avec parfois accumulation d'acides aminés libres. Cependant, chez les animaux insuffisamment adaptés, la digestibilité des glucides pariétaux est souvent réduite ainsi que la protéosynthèse microbienne. Chez les animaux adaptés, ces inconvénients peuvent disparaître notamment en ce qui concerne la digestibilité des glucides pariétaux.

Ces modifications du métabolisme s'expliqueraient en partie par des altérations dans la population microbienne du rumen : les bactéries produisant du formiate et de l'hydrogène, précurseurs de $\mathrm{CH}_{4}$, sont très sensibles à ces antibiotiques tandis que celles produisant du succinate ou utilisant le lactate sont résistantes, conduisant ainsi à une sélection des producteurs de propionate. Dans la pratique, l'emploi du monensin avec des régimes riches en azote non protéique ( $>1$ p. 100 d'urée) et pauvres en protéine végétale risque d'avoir des répercussions défavorables sur le métabolisme azoté de l'hôte.

Les analogues halogénés de méthane sont de puissants inhibiteurs de la méthanogénèse et réduisent parfois l'intensité de la protéolyse. Cependant, ils peuvent avoir des effets négatıfs sur la protéosynthèse microbienne. Leur emploi dans la pratique ne conduit pas régulièrement à une amélioration des performances zootechniques en raison soit d'une adaptation de la flore, soit de l'accumulation d'hydrogène ou d'accepteurs d'hydrogène plus ou moins toxiques.

Les composés diphényliodonium sont efficaces pour inhiber la dégradation des acides aminés dans le rumen. Ils auraient aussi des effets favorables sur les fermentations glucidiques. Des études supplémentaires doivent être entreprises pour s'assurer que ces produits n'altèrent ni la protéosynthèse microbienne ni la cellulolyse.
\end{abstract}

\section{I. - Introduction}

Les aliments ingérés par le ruminant sont en grande partie fermentés dans le premier réservoir gastrique par la micropopulation qui y prolifère. Il en résulte essentiellement une production d'acides gras volatils (AGV), de gaz : gaz carbonique $\left(\mathrm{CO}_{2}\right)$ et méthane $\left(\mathrm{CH}_{4}\right)$, d'ammoniac $\left(\mathrm{NH}_{3}\right)$ et de biomasse microbienne. 
Les acides gras volatils provenant de la dégradation des glucides et des acides aminés sont utilisés par l'hôte comme nutriments énergétiques; ils assurent environ de 65 à 75 p. 100 de l'énergie disponible pour lorganisme; la biomasse, riche en acides aminés essentiels est digérée dans la suite du tube digestif et contribue à la couverture des besoins protéiques de l'hôte.

Par contre, la production de méthane qui peut représenter selon la nature du régime, concentrés ou fourrages, de 6 à 10 p. 100 de l'énergie brute ingérée par lanimal représente une perte énergétique importante pour l'animal. De même, l'azote ammoniacal qui provient de la dégradation des protéines alimentaires, lorsqu'il n'est pas utilisé pour la synthèse des microorganismes, est en grande partie éliminé sous forme d'urée dans l'urine. La valeur azotée des aliments riches en protéines de bonne qualité se trouve donc abaissée lors de leur passage dans le rumen.

Pour mieux valoriser les rations du ruminant, on a recherché des procédés permettant de limiter les pertes d'énergie et d'azote au niveau du rumen sans pour autant réduire les effets bénéfiques de la digestion microbienne qui sont essentiellement : la dégradation des parois végétales et la synthèse de protéine microbienne à partir de diverses formes d'azote non protéique. Divers types d'additifs ont été proposés à cet effet. Afin de comprendre leurs modes d'action au niveau du rumen, leurs avantages et leurs inconvénients éventuels, nous rappellerons quelques aspects des métabolismes glucidique et azoté dans ce premier réservoir gastrique.

\section{II. - Métabolisme au niveau du rumen}

\section{Métabolisme glucidique}

\section{Catabolisme des glucides}

La dégradation des glucides apporte l'énergie nécessaire aux microorganismes pour leur entretien et leur croissance et des nutriments énergétiques à l'hôte, sous forme d'acides gras volatils.

La dégradation des glucides pariétaux est lente et ne débute qu'après une période de latence de quelques heures. Les substances pectiques sont dégradées plus rapidement que les celluloses et les hémicelluloses. Au contraire, la dégradation des glucides de réserve (amidon, fructosanes) est généralement rapide ; elle peut être ralentie par un stockage temporaire dans les bactéries et protozoaires. Les sucres solubles sont dégradés presque instantanément. L'ampleur de la digestion dans le rumen varie selon la nature des glucides, les celluloses étant généralement mieux digérées que les hémicelluloses. Les résultats d'expériences effectuées sur vaches laitières (TAMMINGA, $1979 \mathrm{a}$ ), donnent une moyenne de digestibilité globale apparente de 70 et 84 p. 100 respectivement pour les matières cellulosiques et les extractifs non azotés, dont 89 et 77 p. 100 respectivement seraient dégradés dans le rumen. En général, l'intensité de la digestion des aliments riches en cellulose dans le rumen est fonction du temps de séjour des particules dans ce réservoir.

$\mathrm{Du}$ fait de l'anaérobiose qui règne dans le rumen, les pertes énergétiques au cours de la fermentation des glucides sont importantes : 3 à 12 p. 100 sous forme de chaleur et de 6 à 10 p. 100 sous forme de gaz par rapport à l'énergie brute ingérée. L'obtention d'énergie utilisable pour les biosynthèses microbiennes généralement sous forme d'adénosine triphosphate (ATP) ne représente que 10 à 15 p. 100 
de celle observée en aérobiose; les bactéries devront donc fermenter des quantités importantes de glucides pour assurer leur croissance.

On peut distinguer deux phases dans la dégradation des glucides : l'hydrolyse des chaînes de polysaccharides, puis la fermentation des oses qui en proviennent. La dégradation des oses conduit à la formation de pyruvate dont le catabolisme donne comme produits terminaux principaux : acétate, propionate, butyrate et $\mathrm{CO}_{2}$, ce dernier étant ultérieurement transformé en partie en $\mathrm{CH}_{4}$.

Les principales étapes et voies de la dégradation des glucides dans le rumen sont rappelées dans la figure 1, adaptée d'après TAMMINGA (1979 a).

Lors de la première étape, dégradation des polysaccharides en monosaccharides, de l'ATP peut être éventuellement formé si les phosphorylases interviennent dans l'hydrolyse des disaccharides. La deuxième étape, conversion des monosaccharides en pyruvate, a lieu principalement par la voie Embden-Meyerof et résulte dans la formation de deux moles d'ATP/mole d'hexose ; par la voie du cycle pentose-phosphate approximativement le même nombre d'ATP serait formé (TAMminga, 1979 a). La formation de pyruvate s'accompagne d'une production d'hydrogène $\left(\mathrm{H}^{+}\right)$et de la réduction de cofacteurs en particulier de la nicotinamide adénine dinucléotide (NAD) (formation de $2 \mathrm{NADH}+2 \mathrm{H}^{+}$par mole d'hexose). La quantité de NAD disponible étant limitée, ce cofacteur doit être régénéré $\left(\mathrm{NADH}+\mathrm{H}^{+} \rightarrow \mathrm{NAD}+\right.$ $+\mathrm{H}_{2}$ ) pour que la glycolyse puisse se poursuivre. Cette régénération ne peut se faire que si la pression partielle d'hydrogène $\left(\mathrm{PH}_{2}\right)$ dans le milieu est très basse. La formation de méthane $\left(\mathrm{CH}_{4}\right)$ à partir de gaz carbonique $\left(\mathrm{CO}_{2}\right)$ et de $\mathrm{H}_{2}$ par les bactéries méthanogènes permet de l'abaisser (étape 4).

Le pyruvate (étape 3) peut être converti en acétyl-CoA soit avec production de $\mathrm{CO}_{2}$ et $\mathrm{H}_{2}$ soit avec production de formiate. Dans cette réaction (DEMEYER \& VAN Nevel, 1975), les électrons sont transférés sur des cofacteurs différents du NAD (ferrédoxine...) et ensuite sur des protons (formation de $\mathrm{H}_{2}$ ) ou des protons et du $\mathrm{CO}_{2}$ (formation de formiate) $\left(\mathrm{HCOO}^{-}\right)$. L'acétyl-CoA donne soit de l'acétate, soit du butyrate par $\beta$-oxydation de deux de ses molécules. Le pyruvate peut également donner naissance au propionate selon deux voies : l'une passe par le succinate (voie des acides dicarboxyliques), l'autre passe par le lactyl-CoA (voie réductrice indirecte ou voie acrylate), cette dernière étant prédominante en milieu acide. Les sites supposés de formation et d'utilisation d'ATP sont indiqués sur la figure 1.

Enfin (étape 4) en présence de bactéries méthanogènes (Methano-bacterium ruminantium et $M b$. mobilis), du méthane est formé à partir de $\mathrm{CO}_{2}$ et $\mathrm{H}_{2}$ $\left(\mathrm{CO}_{2}+4 \mathrm{H}_{2} \rightarrow \mathrm{CH}_{4}+2 \mathrm{H}_{2} \mathrm{O}\right)$ ou du formiate $\left(4 \mathrm{HCOOH} \rightarrow 3 \mathrm{CO}_{2}+\mathrm{CH}_{4}+2 \mathrm{H}_{2} \mathrm{O}\right)$ ce dernier pouvant aussi être converti à l'intérieur des cellules en $\mathrm{CO}_{2}$ et $\mathrm{H}_{2}$. Les mécanismes de la méthanogénèse ont été exposés par DemeYer \& VAN Nevel (1975), Il apparaît qu'une mole d'ATP pourrait être formée par mole de $\mathrm{CH}_{4}$ produit.

La formation de $\mathrm{CH}_{4}$ à partir de $\mathrm{CO}_{2}$ permet d'abaisser $\mathrm{PH}_{2}$, et facilite ainsi la formation d'acétate. Lorsque $\mathrm{PH}_{2}$ s'élève, ce qui arrive lorsque le taux de fermentation est important (présence de glucides facilement fermentescibles), le processus s'oriente vers d'autres accepteurs d'électrons tels que propionate, butyrate et lactate afin de régénérer le NADH. C'est aussi le cas en l'absence de bactéries méthanogènes ou en présence d'inhibiteurs de la méthanogénèse. Cette déviation des fermentations sera théoriquement favorable à l'animal puisqu'elle permet de limiter les 
pertes sous forme de $\mathrm{CH}_{4}$. Par contre, elle risque d'entraîner une réduction de l'efficacité de la croissance microbienne (MS synthétisée/mole d'hexose fermentée), en abaissant le rendement énergétique (ATP formé/mole fermentée), surtout si la formation de $\mathrm{CH}_{4}$ à partir de $\mathrm{CO}_{2}$ et $\mathrm{H}_{2}$ produit effectivement une mole d'ATP. Lorsque le taux de renouvellement du milieu est très faible, des «fermentations secondaires » ont aussi été signalées au cours desquelles l'acétate formé serait catabolisé en $\mathrm{CO}_{2}$ et $\mathrm{CH}_{4}$ (Demeyer, 1981 ; Stanier \& Davies, 1981).

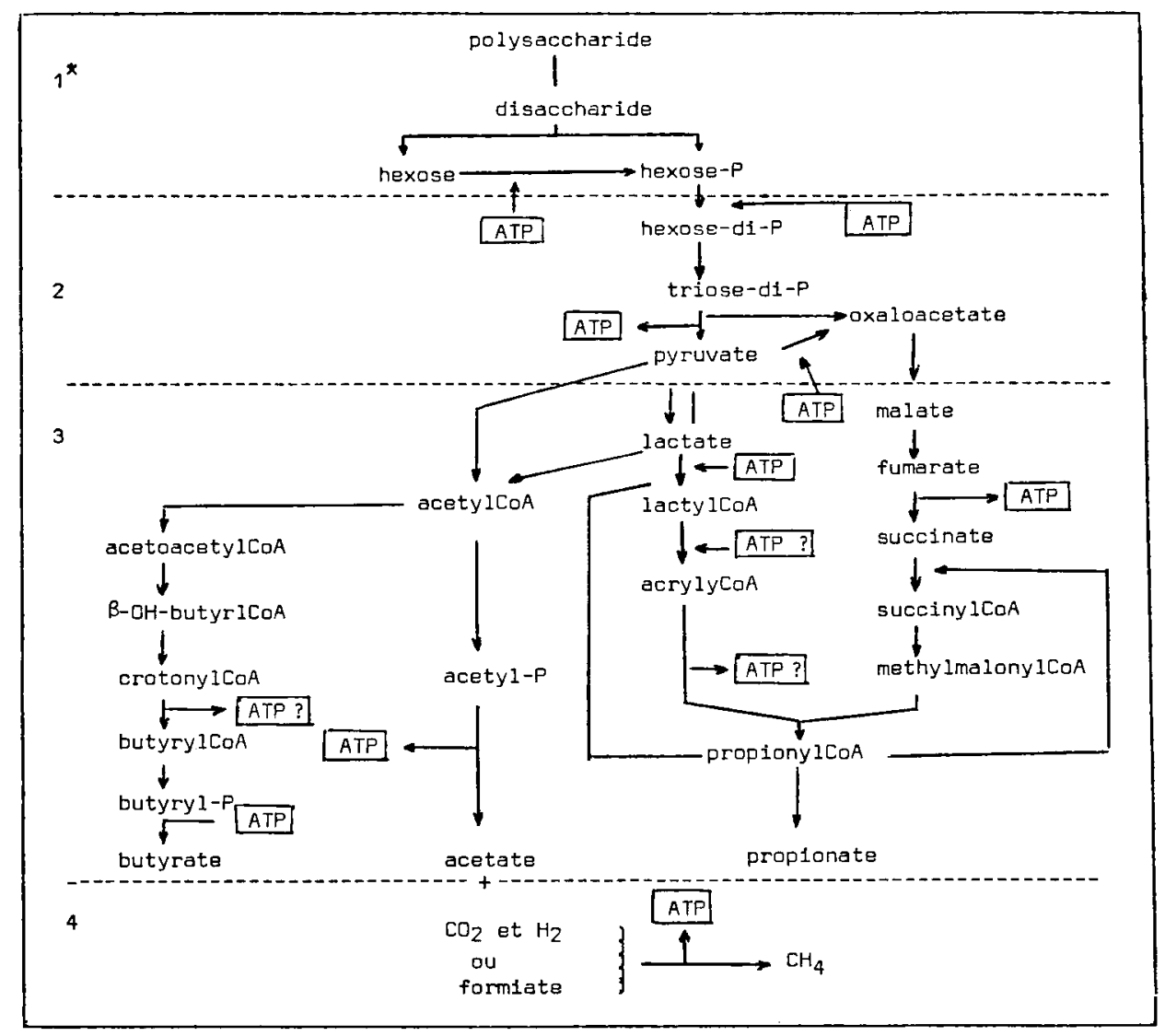

FIG. 1

Schéma simplifié des systèmes de dégradation des glucides dans le rumen (d'après TAMMINGA, $1979 \mathrm{a}$ ).

Simplified pathway for the degradation of carbohydrates in the rumen (from Tamminga, 1979 a).

ATP ? : observé seulement chez certaines souches bactériennes. only observed in some strains of rumen bacteria.

* Principales étapes - Main steps :

1. Dégradation des polysaccharides en monosaccharides.

2. Conversion des monosaccharides en pyruvate.

3. Conversion du pyruvate en acides gras volatils.

4. Réduction du gaz carbonique $\left(\mathrm{CO}_{2}\right)$ et du formiate en méthane $\left(\mathrm{CH}_{4}\right)$. 


\section{TABleau 1}

Estimation de la production d'ATP et d'équivalents hydrogène selon l'acide formé par fermentation d'un équivalent hexose (d'après TAMminga, 1979 a).

ATP yield per hexose equivalent converted to the various acids (from TAMMINGA, 1979 a).

\begin{tabular}{|c|c|c|c|}
\hline & $\begin{array}{c}\text { Production directe } \\
\text { d'ATP }\end{array}$ & $(\mathrm{H})^{\mathrm{c}}$ & $\begin{array}{c}\text { Production totale* } \\
\text { d'ATP }\end{array}$ \\
\hline Acétate & $4-4,5$ & +8 & $5,0-5,5$ \\
\hline Butyrate & $3-3,5$ & +4 & $4,0-5,0$ \\
\hline Propionate $I^{a}$ & $3-6,5$ & -4 & $3,0-6,0$ \\
\hline Propionate $I^{b}$ & $2-2,5$ & -4 & $1,5-2,0$ \\
\hline Lactate ........... & $2-2,5$ & $\mathbf{0}$ & $2,0-2,5$ \\
\hline
\end{tabular}

* Tient compte de la production de $\mathrm{CH}_{4}-$ With $\mathrm{CH}_{4}$ production.

a Voies des acides dicarboxyliques - Dicarboxylic acid pathway.

b Voie «Acrylate» - «Acrylate» pathway.

c Equivalents hydrogènes produits - Hydrogen equivalents produced.

Le tableau 1 (d'après Tamminga, 1979 a) résume les valeurs supposées de formation d'équivalents hydrogènes et d'ATP par équivalent hexose converti dans les différents acides. On voit que lorsque les conditions de milieu sont favorables à une accumulation de lactate ou à une production de propionate par la voie acrylate (pH bas), l'efficacité de la croissance microbienne risque d'être particulièrement réduite.

\section{Faciès jermentaires}

Avec les régimes riches en matières cellulosiques, les fermentations dans le rumen sont régulées en grande partie par les bactéries cellulolytiques qui assurent la disparition des substrats. Les espèces cellulolytiques les plus actives sont Bacteroides succinogenes, Ruminococcus albus, $R$. flavefaciens et, dans une moindre mesure, Butyrivibrio fibrisolvens. Les cellulases sont extracellulaires soit adhérentes aux parois, soit diffusibles dans le milieu (Ruminococcus). Certains protozoaires digèrent aussi la cellulose (DEMEYer, 1981). La plupart de ces organismes adhèrent aux particules alimentaires (CHENG \& Costerton, 1980). Ils réduisent la cellulose en fragments et forment des produits intermédiaires qui seront métabolisés par d'autres groupes bactériens. Ces produits intermédiaires sont généralement : succinate, $\mathrm{H}_{22}$ et formiate. Les produits terminaux sont surtout acétate et butyrate.

La fermentation complète de la cellulose n'est possible que grâce à une population mixte qui comprend selon BRYANT (1973) :

A. cellulolytiques,

B. espèces fermentant les glucides solubles produits par hydrolyse de la cellulose, 
C. espèces dégradant les composés comme l'acide succinique et le formiate et même parfois le lactate produit par le groupe $\mathbf{B}$,

D. bactéries méthanogènes qui utilisent l'hydrogène métabolique ou le formiate produits par les autres espèces pour la formation de $\mathrm{CH}_{4}$, l'énergie libérée étant utilisée pour leur croissance.

Ainsi, même avec des régimes riches en cellulose, les bactéries cellulolytiques ne représentent que le quart de la population bactérienne. De nombreuses interactions métaboliques existent entre ces bactéries comme le montrent clairement les revues de Schwartz \& Gilchrist (1975), de Wolin (1975), de Prins \& Clarke (1980) et de DEMEYER (1981). Lorsqu'on cultive ensemble in vitro des bactéries cellulolytiques et méthanogènes, les substrats sont mieux dégradés et la production d'acétate est accrue (WOLIN, 1975).

Les glucides de réserve et les sucres solubles sont fermentés par de nombreuses espèces bactériennes qui produisent de l'acétate et du propionate comme produits terminaux et comme produits intermédiaires du succinate (ex. Bacteroides amylophilus, Selenomonas ruminantium) et du lactate (Streptococcus bovis et Lactobacillus $s p . .$.$) . Ce dernier acide sera dégradé par un autre groupe bactérien (Megasphera$ elsdenii, Selenomonas lactilytica et ruminantium, Veillonella alcalescens...).

Il existe aussi entre ces espèces et les méthanogènes des interactions métaboliques, ainsi Selenomonas ruminantium, en présence de méthanogènes, produit davantage d'acétate à partir de l'acide lactique avec un meilleur rendement énergétique pour la flore (Prins \& Clarke, 1980).

Ainsi, les proportions relatives des différents acides dans le rumen pourront être, pour une part, fonction de l'activité des bactéries méthanogènes.

Les facies classiques observés in vivo varient avec la nature des aliments distribués. Avec les fourrages, le facies fermentaire est généralement caractérisé par une prépondérance de l'acétate (pourcentage molaire : 65 à 75 p. 100); le propionate et le butyrate ne représentent que 20 ou 10 p. 100 des AGV.

La dégradation de la cellulose est lente, les méthanogènes sont en grand nombre. La stabilité cie ce type fermentaire est assurée par une salivation abondante qui maintient le $\mathrm{pH}$ aux environs de 6,3 - 7,0. De plus, le taux de renouvellement de la phase liquide du contenu de rumen, appelé encore taux de dilution (fraction du volume de liquide qui quitte le rumen par heure) est relativement élevé (5 à 12 p. 100 par heure) avec les fourrages (Prins \& Clarke, 1980).

Avec les céréales, le nombre de bactéries cellulolytiques diminue; les méthanogènes se multiplient mal ( $\mathrm{pH}$ trop acide) ; le nombre des amylolytiques et des producteurs d'acide lactique augmente, le facies fermentaire devient «propionique " et parfois «butyrique». Le propionate peut parfois atteindre 40 p. 100 et plus des AGV totaux. Le taux de renouvellement de la phase liquide devient faible ( 3 à 5 p. 100 par heure).

La période d'adaptation au régime concentré a une importance considérable. Lorsqu'elle est longue, les protozoaires joueront le rôle de régulateur de fermentation en captant l'excès de glucides. Les bactéries fermentant le lactate en acide propionique ou butyrique pourront s'établir et on n'observera pas d'accumulation d'acide lactique. Avec un changement brutal d'un régime fourrage à un régime concentré, 
l'acide lactique, produit en grande quantité, provoque une forte acidité, ce qui empêchera l'implantation des protozoaires et des bactéries fermentant le lactate. L'absorption de l'acide lactique pourra provoquer des troubles chez l'animal (acidose).

D’une façon générale, les facies fermentaires de type céréales sont instables du fait des variations de $\mathrm{pH}$ et d'une salivation réduite.

Pour l'animal hôte, le facies propionique se traduira par une réduction des pertes d'énergie, de plus, l'acide propionique est généralement considéré comme favorable aux métabolismes énergétique et azoté. Les besoins énergétiques de précurseurs de glucose varient selon l'intensité de la croissance ou de la production laitière. Ils se situent entre 10 et 40 p. 100 de l'énergie métabolisable (OrsKov, 1980). Lorsque la proportion d'acide propionique produit dans le rumen s'élève, la proportion d'énergie, sous forme de précurseur de glucose, s'élève également ( 21 p. 100 pour 15 p. 100 d'acide propionique, 48 p. 100 pour 35 p. 100 d'acide propionique).

Rappelons cependant que des teneurs élevées en acide propionique réduisent la teneur en matière grasse du lait et que les capacités de l'animal à métaboliser efficacement l'acide propionique peuvent parfois être dépassées.

\section{Métabolisme azoté}

\section{Dégradation des protéines dans le rumen}

Les protéines alimentaires sont en partie dégradées par les bactéries et les protozoaires. De nombreuses espèces bactériennes sont protéolytiques (en particulier Selenomonas, Butyrivibrio, Bacteroides...). Les protéases bactériennes sont liées aux cellules et fixées en surface, elles sont composées d'exo et d'endopeptidases. Les peptides et acides aminés formés sont ensuite transportés à l'intérieur des cellules et sont soit incorporés dans les protéines bactériennes, soit dégradés en $\mathrm{NH}_{3}, \mathrm{AGV}$, $\mathrm{CO}_{2}$ et parfois $\mathrm{CH}_{4}$. Les produits terminaux sont excrétés dans le milieu extérieur; quelques acides aminés (diacides, alanine, glycine) peuvent aussi être excrétés (DEMEYER \& VAN NeVEL, 1980). L'alanine serait synthétisée lors d'un excès de précurseurs $\left(\mathrm{NH}_{3}\right.$, acide pyruvique) et servirait de forme de réserve d'azote. La dégradation des acides aminés se fait par désaminations, transaminations et décarboxylations.

Le processus de décarboxylation conduisant à la synthèse d'amines n'est important que lorsque le milieu est acide. La désamination, suivie de décarboxylation qui procure de l'ATP aux bactéries, semble être la voie la plus classique. Les cofacteurs réduits formés, devront être oxydés avec la formation de propionate, butyrate ou $\mathrm{CH}_{4}$.

Il existe de grandes variations entre les souches ou espèces bactériennes dans la capacité d'incorporer et de dégrader les acides aminés (Chalupa, 1978); ces différences peuvent être liées aux phénomènes de transport à travers la paroi. Il semblerait, d'après des études in vivo (TAMMINGA, 1979 b) que les acides aminés les plus susceptibles d'être dégradés sont l'arginine, les acides aspartique et glutamique, la proline et l'alanine; par contre, la méthionine serait nettement moins dégradée.

Chez les protozoaires, la protéolyse se situe à l'intérieur de la cellule à partir des particules alimentaires et des bactéries qu'ils ingèrent. Les protozoaires peuvent 
aussi excréter les acides aminés qu'ils n'utilisent pas pour leur synthèse (TAMminga, $1979 \mathrm{~b})$.

Généralement, la dégradation des protéines alimentaires par les microorganismes excède largement leurs propres besoins en acides aminés. Il s'ensuit une production de $\mathrm{NH}_{3}$ dans le milieu de rumen. Dans les conditions normales d'alimentation on ne retrouve par contre que très peu d'acides aminés libres (valeurs inférieures à $20 \mathrm{mg} \mathrm{N} / 1$ ), ceux-ci étant rapidement métabolisés.

L'intensité de la dégradation des protéines dans le rumen dépend de nombreux facteurs propres à l'aliment (solubilité, structure) (I.N.R.A., 1978 ; TAMmingA, 1979 b), mais elle est aussi fonction de leur temps de séjour dans le rumen.

\section{Synthèse de protéine microbienne}

La biomasse comprend des bactéries et des protozoaires. Les protozoaires peuvent représenter, selon le type d'aliment, entre 45 et 85 p. 100 de la biomasse totale (Harrison \& MCAllan, 1980), les valeurs les plus élevées étant obtenues avec des régimes concentrés. Il semble que la proportion de protozoaires qui quitte le rumen soit relativement réduite. La contribution des protozoaires dans l'apport d'acides aminés à l'hôte est mal connue actuellement.

Les différents facteurs susceptibles d'influencer la croissance des cellules microbiennes dans le rumen ont été clairement énoncés par BERgen \& YoKoyama, 1977. Nous rappelons ici quelques données concernant l'énergie, l'azote et le taux de dilution.

\section{Energie}

Le rendement optimum de transformation de l'ammoniac en protéine ne peut être obtenu que lorsqu'il y a une simultanéité entre présence d'ammoniac et fermentations glucidiques produisant les ATP nécessaires à son utilisation (I.N.R.A., 1978).

Le rendement avec lequel les bactéries utilisent les ATP formés varie assez considérablement. En moyenne in vivo 10 à $15 \mathrm{~g}$ de MS bactérienne seraient produits par mole d'ATP (Tamminga, 1979 a). Pratiquement, on exprime le plus souvent l'efficacité de la protéosynthèse microbienne en azote microbien ou matière azotée $(\mathrm{N} \times 6,25)$ synthétisée par rapport à la matière organique fermentée dans le rumen (MOF).

Les valeurs rapportées varient entre 25 et $40 \mathrm{~g} \mathrm{~N} / \mathrm{kg}$ MOF. De nombreux facteurs peuvent réduire l'efficacité. Ces facteurs sont soit d'origine alimentaire (carence en éléments indispensables à la croissance bactérienne, présence de produits toxiques envers certaines bactéries), soit liés à la physiologie de l'animal (transit, salivation), ou à la présence de certains microorganismes prédateurs (protozoaires).

\section{Azote}

L'ammoniac est un précurseur important de la protéosynthèse microbienne. Pour Harrison \& McAllan (1980), une des principales enzymes impliquées dans l'incorporation de $\mathrm{NH}_{3}$ est la glutamine synthétase. Elle a une grande affinité pour l'ammoniac et la réaction serait maximale pour une concentration intracellulaire de 
28-42 mg N/l. En général, des concentrations de $\mathrm{NH}_{3}$ dans le milieu, comprises entre 30 et $80 \mathrm{mg} \mathrm{N} / 1$ suffisent à assurer la protéosynthèse microbienne maximale. Parfois, des concentrations supérieures sont nécessaires $(238 \mathrm{mg} \mathrm{N} / 1)$. Ce fait s'expliquerait par le rôle de la glutamate deshydrogénase qui a une faible affinité pour $\mathrm{NH}_{3}$ et pour laquelle la vitesse maximale d'incorporation de $\mathrm{NH}_{3}$ ne serait atteinte qu'avec des taux de $\mathrm{NH}_{3}$ de 168 à $252 \mathrm{mg} \mathrm{N} / 1$. Ainsi, les variations observées in vivo dans les taux de $\mathrm{NH}_{3}$ requis s'expliquent par des variations dans les mécanismes d'incorporation. S'il est reconnu, actuellement, que les bactéries peuvent utiliser directement des acides aminés préformés, il n'en reste pas moins qu'en l'absence de protéine dégradable, la protéosynthèse microbienne est considérablement réduite par un appauvrissement du milieu en $\mathrm{NH}_{3}$. L'ammoniac est, de plus, indispensable à la croissance de certaines bactéries cellulolytiques. Une teneur en $\mathbf{N H}_{3}$ trop faible du milieu peut aussi conduire à un "découplage» des fermentations (production d'acides sans croissance bactérienne); on assiste alors à une production d'acides gras volatils normale avec une synthèse de protéine microbienne très réduite, ce qui abaisse considérablement l'efficacité de la protéosynthèse.

\section{Taux de renouvellement de la phase liquide du rumen}

Il est actuellement reconnu que l'efficacité de la protéosynthèse dépend, pour une large part du taux de renouvellement de la phase liquide (Harrison \& McAllan, 1980). Récemment Stanier \& Davies (1981) ont montré qu'un abaissement du taux de renouvellement dans un fermenteur en continu pouvait réduire de 43 p. 100 le rendement de la protéosynthèse. Ainsi, à un taux de renouvellement (TR) faible correspond un mauvais rendement de croissance; dans cette situation, la part de l'énergie disponible, qui est utilisée pour couvrir les besoins d'entretien des microorganismes, est particulièrement importante. Dans un exemple, cité par Harrison \& MCAllaN (1980), le pourcentage des ATP produits utilisés pour l'entretien qui serait de 12 p. 100 pour une valeur de TR de 11 p. 100 , passerait à 32 p. 100 pour une valeur de TR de 3,2 p. 100. Il s'ensuit que les régimes fourrages (TR élevés) entraînent souvent une meilleure efficacité de synthèse protéique que les régimes concentrés (TR faibles).

\section{III. - Effet des additifs sur le métabolisme du rumen}

\section{Antibiotiques ionophores}

Plusieurs antibiotiques ionophores ont la propriété d'accroître la production d'acide propionique des cultures mixtes de microorganismes du rumen. Parmi ceux-ci, seul le monensin est autorisé actuellement à être incorporé aux aliments des ruminants. Parmi les autres antibiotiques ionophores expérimentés in vitro et in vivo, nous retiendrons plus particulièrement le lasalocide et citerons quelques effets de la salinomycine.

\section{Structure et action : généralités}

Les antibiotiques ionophores ont une activité anti-microbienne grâce à leurs effets sur la perméabilité membranaire spécifiquement pour le passage de certains cations. 
Les antibiotiques apparemment les plus actifs au niveau du rumen appartiennent au type "polyether»; ils ont été isolés à partir de cultures de Streptomyces. Ils ont la capacité de former des complexes lipidosolubles qui servent de véhicules à une large variété de cations pour traverser la membrane (WESTLEY, 1977). Ils contiennent un nombre important de tétrahydropyrane et de furane dans leurs molécules (fig. 2). On distingue les composés qui ne peuvent transporter exclusivement que des cations monovalents, c'est le cas du monensin et de la salinomycine, des composés qui transportent à la fois les cations mono et divalents comme le lasalocide. Les séquences d'affinité ionique sont les suivantes :

Monensin

et

$$
\mathrm{Na} \gg \mathrm{K}>\mathrm{Rb}>\mathrm{Li}>\mathrm{Cs}
$$

Salinomycine

Lasalocide

$$
\begin{aligned}
& \mathrm{Cs}>\mathrm{Rb}, \mathrm{K}>\mathrm{Na}>\mathrm{Li} \\
& \mathrm{Ba}>\mathrm{Ca}>\mathrm{Mg}
\end{aligned}
$$

\section{Monensin}

C26

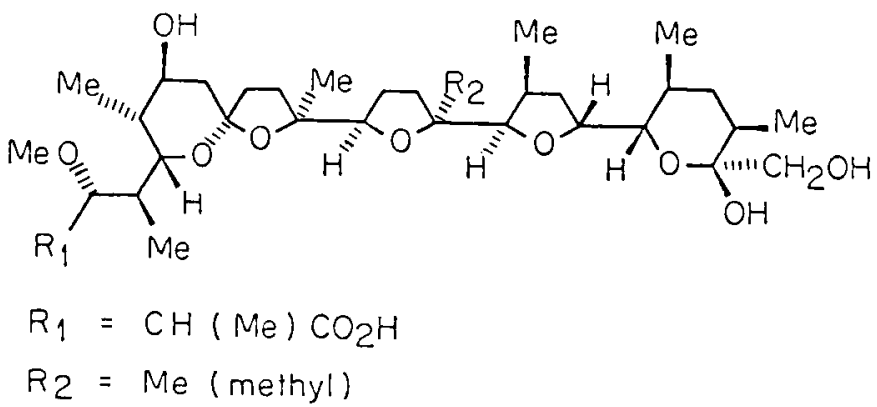

Salinomycine

C30

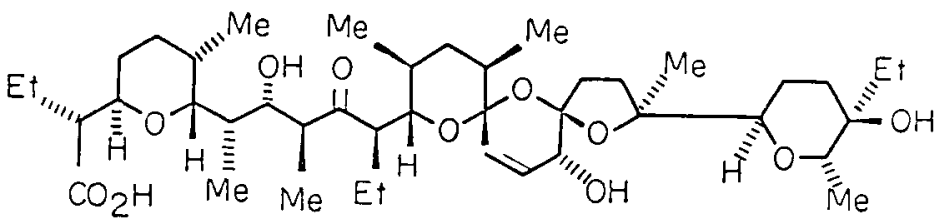

Lasalocide

C36

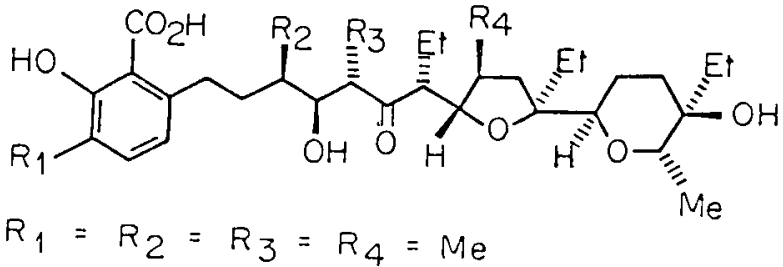

Fig. 2

Structure des antibiotiques ionophores "polyethers》 (d'après WESTLEY, 1977).

Structure of some ionophores : polyether antibiotics (from WESTLEY, 1977). 


\section{TABLEAU 2}

Sensibilité des bactéries du rumen aux antibiotiques ionophores (d'après les résultats de Chen et Wolin, 1979 et Dennis, Nagaraja et Bartley, 1981 a).

Sensitivity of rumen bacteria to "ionophores 》 antibiotics (from the results of Chen and Wolin, 1979 and Dennis, Nagaraja and Bartley, 1981 a).

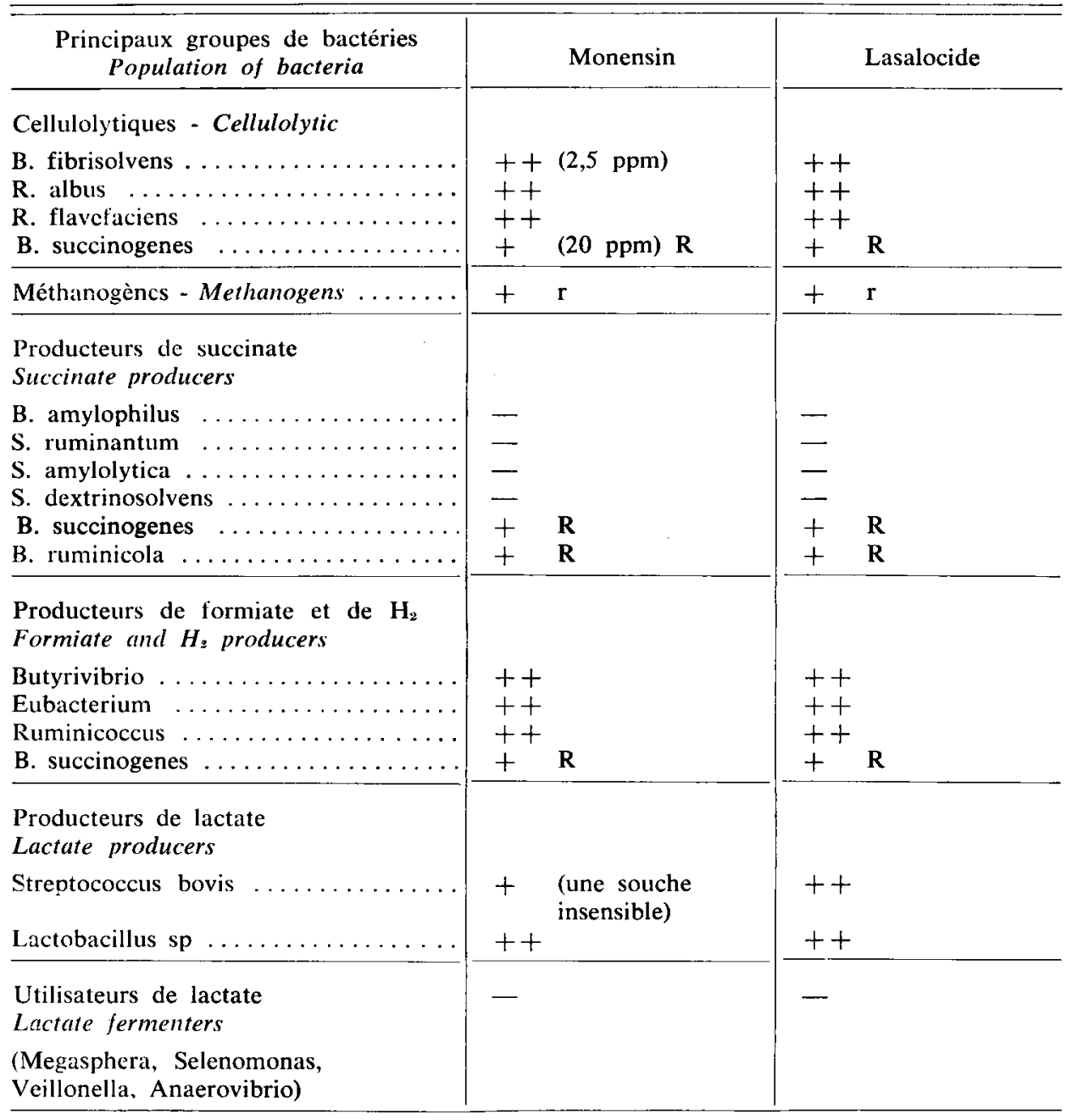

r Retard de croissance - Delayed growth.

$\mathrm{R}$ Acquisition de résistance - Selection for resistance.

$+\quad$ Faible sensibilité - moderately sensitive.

++ Forte sensibilité - Highly sensitive.

- Insensible - Insensitive. 
Ces produits ont une activité anticoccidienne (les coccidies font partie des protozoaires) largement reconnue et utilisée. Leur activité envers les bactéries semble spécifique sur les bactéries Gram positives $\left(G^{+}\right)$, donc dépend de la nature des parois. Parmi les espèces étudiées par WestLey (1977), les bacilles apparaissent les plus sensibles in vitro, les cocci et les bactéries filamenteuses étant aussi inhibés, les doses inhibitrices minimales allant de 0,2 à $12 \mathrm{ppm}$ du milieu. Cet auteur considère que l'inhibition microbienne est probablement due aux pertes de la cellule en cations monovalents essentiels comme le $\mathbf{K}^{+}$. En effet, l'activité de certains ionophores peut être inversée par addition d'un excès d'ions $\mathrm{K}+$ dans le milieu. Il est bien connu (TEMPEST, 1969), que $\mathrm{K}$ est un des constituants importants (40-49 $\mathrm{mg} / \mathrm{g} \mathrm{MS}$ pour Bacillus) et essentiels des cellules bactériennes notamment pour la synthèse protéique. Cet auteur rapporte que le remplacement de $\mathrm{K}$ par $\mathrm{Na}$ chez Streptococcus faecalis n'inhibait pas la glycolyse, mais stoppait la protéosynthèse.

\section{Influence sur la digestion dans le rumen in vitro}

\section{a. Croissance des bactéries du rumen en culture pure}

Deux expériences récentes ont mis en évidence l'effet du monensin et du lasalocide de sodium d'une part sur la croissance des espèces bactériennes importantes pour la fermentation des glucides pariétaux et de réserve (Ruminococcus, Butyrivibrio, Bacteroides, Selenomonas), et sur celle des méthanogènes (CHEN \& Wolin, 1979) et, d'autre part sur la croissance des bactéries produisant et utilisant le lactate (Dennis, Nagaraja \& Bartley, 1981 a).

Les résultats des deux expériences concernant les principaux groupes bactériens sont rapportés dans le tableau 2.

En général, seules les bactéries $\mathbf{G}^{+}$à la coloration ou qui ont une structure de paroi $\mathbf{G}^{+}$comme $B$. fibrisolvens sont sensibles. Les espèces qui sont inhibées donnent surtout de lacétate et du butyrate comme produits terminaux et de l'hydrogène et du formiate comme produits intermédiaires précurseurs de $\mathrm{CH}_{4}$. Leur inhibition tendrait à baisser la production de $\mathrm{CH}_{4}$, d'acétate et de butyrate dans le rumen. Parmi les espèces sensibles, on retrouve aussi les bactéries produisant du lactate. On remarque que la sensibilité de différentes souches de Streptococcus bovis est plus large pour le lasalocide que pour le monensin. D'autre part, en ce qui concerne les deux isomères, le monensin a un effet inhibiteur plus marqué sur la production de L-lactate que de D-lactate. Les espèces résistantes se retrouvent parmi celles qui produisent du succinate comme produit intermédiaire et celles qui utilisent le lactate. Le succinate est un précurseur de propionate et le lactate peut être principalement fermenté en propionate (surtout dans les régimes riches en céréales).

En résumé, les antibiotiques ionophores ont un effet antibactérien très net sur les bactéries de structure $\mathrm{G}^{+}$. Cet effet pourrait être dû à une sortie de la cellule de cations monovalents comme le potassium. Or, l'on sait que cet élément est essentiel à la croissance des bactéries du rumen (Durand \& Kawashima, 1980). Selon une autre hypothèse (Chalupa, 1980), ces antibiotiques entraîneraient une entrée accrue de sodium dans la cellule, et seuls les organismes les plus tolérants au sodium résisteraient. Il a été effectivement montré par Caldwell (dans Durand \& KaWASHima, 1980) que les Bacteroides $s p$ ont un besoin de $\mathrm{Na}$, les bactéries du rumen étant plus ou moins halophiles. 


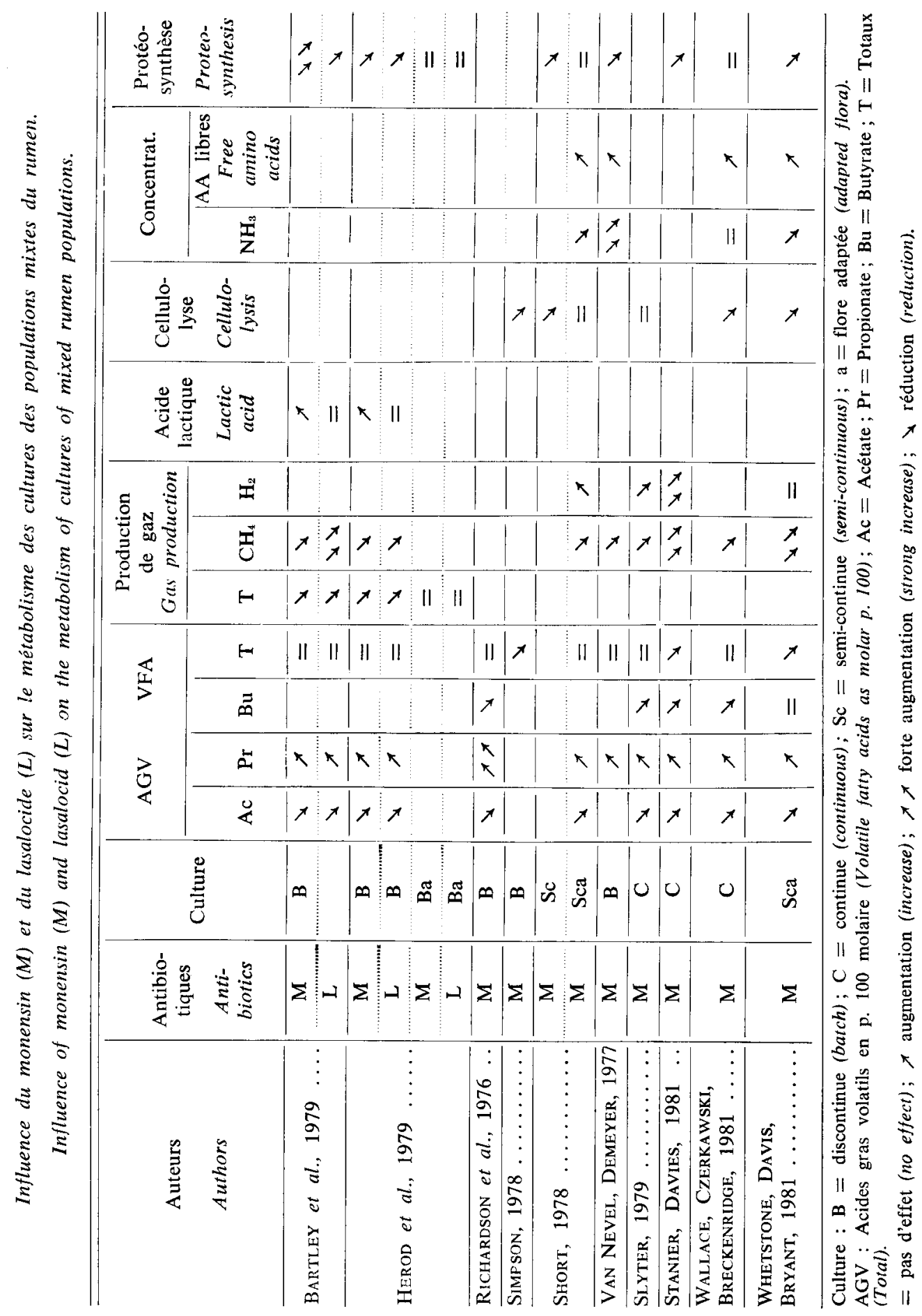


Les conséquences métaboliques résultant d'une altération de la population du rumen par ces produits ont été présentées par CHEN \& Wolin, 1979. Ces antibiotiques augmenteraient la production de propionate en sélectionnant les bactéries qui produisent le succinate et celles qui fermentent le lactate. L'inhibition des organismes qui produisent du formiate et de l'hydrogène, précurseurs de $\mathrm{CH}_{4}$, pourrait réduire la production de ce dernier. Cependant, ces organismes comprennent une fraction importante de bactéries cellulolytiques. L'activité cellulolytique pourrait donc s'en trouver réduite comme nous allons le voir ci-dessous.

Le lasalocide, et dans une moindre mesure le monensin, pourrait aussi limiter les risques d'acidose lactique du fait de la sensibilité des bactéries lactiques à ces produits.

\section{b. Métabolisme des cultures de populations mixtes}

Ces cultures sont de plusieurs types. Elles sont réalisées en utilisant comme inoculum du jus de rumen prélevé soit sur des animaux recevant un régime standard, soit sur des animaux adaptés aux produits étudiés. Elles sont maintenues pendant des temps courts (de quelques heures à 48 heures au maximum), cultures discontinues ou cultures en «batch», ou pendant des temps longs, cultures semi-continues ou continues (durant plus de 15 jours). Nous avons résumé les résultats de quelques expériences in vitro (Tableau 3).

Quel que soit le mode de culture, on observe pratiquement toujours une augmentation du pourcentage molaire de propionate accompagné d'une baisse de celui d'acétate et parfois de butyrate. Toutefois, dans l'expérience de VAN Nevel \& DEMEYER (1977), ce résultat n'était pas toujours significatif. Cette orientation du facies s'accompagne pratiquement toujours d'une réduction de la production de $\mathrm{CH}_{4}$, lorsque celle-ci est mesurée. Le lasalocide a pratiquement le même effet que le monensin, bien que l'inhibition de production de méthane puisse être encore plus accentuée (BARTLEY et al., 1979).

L'orientation des fermentations par le monensin serait bien due comme l'ont suggéré CHEN \& Wolın (1979) à une altération de la population du rumen. En effet, les résultats récents de Wallace, Czerkawski \& Breckenridge (1981) obtenus avec des fermentations de longue durée (technique de simulation des fermentations «Rusitec») montrent une réduction dans le nombre des cocci $\mathrm{G}^{+}$et une augmentation des bâtonnets $\mathbf{G}^{-}$alors que le nombre total des bactéries reste inchangé ; parallèlement, ces auteurs observent une augmentation de l'activité de la succinate déshydrogénase confirmant ainsi que cet additif entraîne une production accrue de succinate précurseur de propionate.

Le monensin accroît parfois (tableau 3) la production de lactate, qui est comme le propionate, un accepteur d'électrons. Par contre, ce n'est pas le cas du lasalocide ce qui est aussi en accord avec les résultats des cultures pures.

Dans plusieurs essais (tableau 3), la réduction de l'ammoniac formé et l'accumulation des acides aminés libres dans les milieux en présence de monensin indiquent que ce produit réduirait l'ampleur de la dégradation des protéines. Les résultats récents de Whetstone, Davis \& Bryant (1981), obtenus en culture semi-continue, confirment cet effet du monensin: protection d'une partie de la caséine utilisée comme substrat et des peptides qui en proviennent. 
Par contre, deux effets défavorables des produits sont parfois observés : la réduction de la cellulolyse et de la protéosynthèse microbienne. Une réduction de la cellulolyse s'explique par les résultats des cultures pures : inhibition spécifique de certaines bactéries cellulolytiques. Selon Wallace, Czerkawski \& Breckenridge (1981), l'intensité de la réponse dépend de la nature des glucides membranaires, et des classes de bactéries cellulolytiques qui interviennent. En effet, ces derniers auteurs observent, encore après un mois de culture, l'effet inhibiteur du monensin et Whetstone, Davis \& BRYANT (1981) l'observent également avec un inoculum provenant d'animaux adaptés contrairement à SHORT (1978). L'effet inhibiteur sur la protéosynthèse microbienne se retrouve dans toutes les incubations effectuées avec des inoculum non adaptés aux produits, que ce soit avec le monensin ou, dans une moindre mesure, avec le lasalocide. Pour Van Nevel \& Demeyer (1977), il y aurait un découplage des fermentations (fermentation glucidique sans synthèse), donc une baisse de l'efficacité de protéosynthèse. Cet effet défavorable pourrait être dû soit à une réduction du nombre de bactéries à croissance active, soit à une baisse du rendement énergétique (ATP/hexose) que nous avons évoqué précédemment, soit à un effet spécifique des cations sur les transports cellulaires. La carence en $\mathrm{K}$, nous l'avons vu, peut inhiber la protéosynthèse sans affecter la glycolyse. Cependant, comme pour la cellulolyse dans certaines expériences, cet effet négatif du monensin sur la protéosynthèse n'est pas retrouvé lorsque l'inoculum provient d'animaux adaptés (tableau 3).

\section{Influence sur la digestion dans le rumen in vivo}

\section{a. Métabolisme glucidique}

\section{- Acides gras volatils}

De très nombreuses expériences ont montré l'effet du monensin sur l'élévation de la proportion d'acide propionique dans le rumen. Les résultats de Dinius, Simpson \& MARSH (1976), obtenus aux Etats-Unis sur taurillons consommant des fourrages et ceux de Jouany \& Senaud (1978), obtenus en France sur moutons recevant un régime mixte fourrage-concentré, sont particulièrement probants. L'élévation du pourcentage de propionate s'accompagne généralement d'une baisse de celui de l'acétate et parfois du butyrate. Des résultats semblables ont été obtenus au Japon sur bouvillons recevant un régime concentré (SAKAUCHI, WaRita \& Hoshino, 1979) et également en Italie avec un régime ensilage de maïs distribué ad libitum (PARISINI, RIzZI \& SCIPIONI, 1979). L'action du monensin semble donc être indépendante de la nature du régime. Parfois, cependant le monensin n'a pas accru le pourcentage d'acide propionique et ce, avec différents types de régime : teneur élevée en sorgho (MuNTIFERING et al., 1980), mélange orge et luzerne condensée (JoHnson et al., 1979 ; Dyer et al., 1980) ou grains entiers de maïs (LyLE, Johnson, Backus, 1981). Cette absence d'action se manifeste généralement lorsque la proportion d'acide propionique dans le régime témoin est déjà très élevée.

En ce qui concerne les animaux au pâturage, les résultats sont contradictoires : HoRN et al. (1981) observent un accroissement très significatif du propionate (de 23 à 28,2 p. 100), effet non observé par RichaRdSON et al. (1976). 
Par rapport au monensin, le lasalocide aurait, selon les cas, soit le même effet (Herod et al., 1979), soit un effet moins accentué (THONNEY et al., 1981). La salinomycine accroît également le pourcentage d'acide propionique (MCCLuRE et al., 1980 ; WebB, Fontenot \& Lucas, 1980).

En général, avec les régimes fourrages, il y a une relation étroite entre les pourcentages molaires des AGV et les proportions dans lesquelles ils sont produits. Par contre, cette relation est beaucoup plus incertaine pour des régimes comprenant de 60 à 90 p. 100 de concentré (SUTTON, 1980) sans doute du fait de différences dans les vitesses d'absorption de chaque acide. Aussi, des auteurs ont mesuré l'effet du monensin sur la production totale dacide propionique (moles/j) en utilisant des techniques de dilution isotopique (VAN MaAnen et al., 1978 ; Prange, Davis \& Clark, 1978) ou des mesures in vitro parallèlement à la digestion in vivo (Shell, Hale \& Theurer, 1979). Les résultats suivants ont été obtenus :

\begin{tabular}{|c|c|c|c|c|}
\hline \multirow{2}{*}{ Régimes } & \multicolumn{2}{|c|}{$\begin{array}{c}\text { VAN MAANEN } \text { et al. } \\
1978\end{array}$} & \multirow{2}{*}{$\begin{array}{c}\text { P'range, Davis } \\
\text { et Theurer, } \\
1978 \\
\text { Mixte }\end{array}$} & \multirow{2}{*}{$\begin{array}{c}\begin{array}{c}\text { Shell, Hale } \\
\text { et Theurer, } \\
1979\end{array} \\
\text { Concentré }\end{array}$} \\
\hline & Fourrages & Céréales & & \\
\hline $\begin{array}{l}\text { Témoin } \\
\text { Monensin }\end{array}$ & $\begin{array}{l}5,5 \\
8,2\end{array}$ & $\begin{array}{r}6,4 \\
11,2\end{array}$ & $\begin{array}{r}7,7 \\
11,2\end{array}$ & $\begin{array}{r}7,3 \\
11,8\end{array}$ \\
\hline
\end{tabular}

Quel que soit le type de régime, le taux de production du propionate a été considérablement accru, confirmant bien les observations effectuées sur les pourcentages molaires des concentrations dans le rumen.

On observe souvent une baisse de la concentration en AGV totaux sous l'effet du monensin (ex. : Jouany \& Senaud, 1978 : - 20 p. 100 ; Prange, Davis \& Clark, 1978 : - 13 p. 100) ; cette baisse est d'autant plus importante que la concentration en AGV du régime témoin est plus élevée (GEAY, communication personnelle). Par contre, la chute considérable (-55 p. 100) obtenue par Oltjen, Dinius \& Gering (1977) avec des bouvillons recevant $180 \mathrm{mg}$ de monensin/j avec un régime pauvre (80 p. 100 de coques de coton, supplément azoté : urée 80 - soja 20) s'est accompagnée d'une forte réduction du gain de poids des animaux. Les réductions dans les concentrations en AGV totaux peuvent provenir, en partie, de la réduction des quantités ingérées souvent observée avec le monensin notamment dans l'expérience de Oltjen, Dinius \& Geering (1977).

\section{- Acide lactique}

Comme in vitro, in vivo, on observe parfois un accroissement de la teneur en acide lactique avec le monensin (JounNy \& Senaud, 1978). Cependant, à la fois, le monensin et le lasalocide ont permis d'éviter l'acidose lactique induite expérimentalement par introduction dans le rumen de glucose ou de maïs en farine (NAGARAJA et al., 1981), ce qui présente un intérêt pratique certain lors des changements brutaux des régimes fourrages aux régimes concentrés. 


\section{- Méthane}

La réduction de la formation de $\mathrm{CH}_{4}$, déjà observée in vitro est in vivo particulièrement importante dans les premières heures suivant le repas (Jouany \& SEnaud, 1978) notamment avec des régimes riches en paroi végétale (THORNTON \& OWENS, 1981). La salinomycine a un effet analogue sur taurillons (WEBB, Fontenot \& LUCAs, 1980).

\section{- Digestibilité des matières cellulosique et organique}

La digestibilité de la matière cellulosique avec le monensin peut être soit abaissée dans les 15 premiers jours (Poos, Hanson \& Klopfenstein, 1979) soit inchangée (ZinN, Sharp \& OWEns, 1980) ou accrue : avec un régime à 80 p. 100 de concentré, elle s'accroît de +15 p. 100 (Thompson \& RiLex, 1980) et de +18 p. 100 avec un régime mixte (Horton \& Nicholson, 1980). Aussi, il semble bien qu'in vivo, le phénomène d'adaptation parfois observé in vitro se retrouve en ce qui concerne la cellulolyse (Poos, Hanson \& KLopfenstein, 1979).

L'élévation de la digestibilité des parois peut être due à la réduction des quantités consommées et aussi à un allongement du temps de séjour des particules dans le rumen, chacun de ces phénomènes pouvant influencer l'autre. LemENAGER et al. (1978 a) ont effectivement montré que le taux de renouvellement de la phase solide du contenu de rumen est abaissé par la distribution du monensin avec un régime fourrage pauvre $(1,5$ p. 100 contre 2,7 p. 100).

La salinomycine aurait un effet dépressif net sur la digestibilité de la matière cellulosique (WebB, Fontenot \& LuCAs, 1980).

L'effet du monensin sur la digestibilité de la matière organique (MO) dans le rumen semble dépendre de la nature du régime. Muntifering, Theurer \& Noon (1981) montrent avec un régime de maïs grains entiers que la MO réellement digérée dans le rumen de bouvillons décroît de 21 p. 100, tandis que la digestibilité globale reste identique; ce déplacement du site de la digestion du rumen vers l'intestin avec les régimes concentrés pourrait être favorable à l'hôte en évitant les pertes énergétiques de fermentation et en augmentant l'apport de glucose (MunTIFERING, THEL RER \& NoON, 1981). Par contre, avec des moutons consommant de l'herbe sèche, AlleN \& HARrison (1979) montrent que la MO, apparemment fermentée dans le rumen, et la production d'AGV sont accrues respectivement de 9 et 8 p. 100 par le monensin, sans doute, comme déjà signalé pour les glucides de paroi, par l'allongement du temps de séjour des particules dans le rumen; le taux de renouvellement de la phase liquide a été effectivement réduit dans cette expérience de 7 p. 100 pour le témoin à 4 p. 100 par heure en présence de monensin.

\section{b. Métabolisme azoté}

\section{- Dégradation des protéines alimentaires}

Une réduction souvent significative des concentrations en $\mathrm{N}-\mathrm{NH}_{3}$ dans les contenus de rumen a été observée dans de nombreuses expériences (tableau 4). Dans certains cas, une élévation des teneurs en acides aminés libres est aussi notée (244 contre $110 \mathrm{mg} / 100 \mathrm{~g}$ de contenu) (HoRTON, 1979), ce qui témoignerait d'une inhibitíon partielle du transport des acides aminés vers l'intérieur de la cellule microbienne. 


\section{TABleau 4}

Influence du monensin sur les concentrations en $\mathrm{N}-\mathrm{NH}_{3}$ dans le liquide de rumen.

Influence of monensin on ammonia concentrations in ruminal fluid.

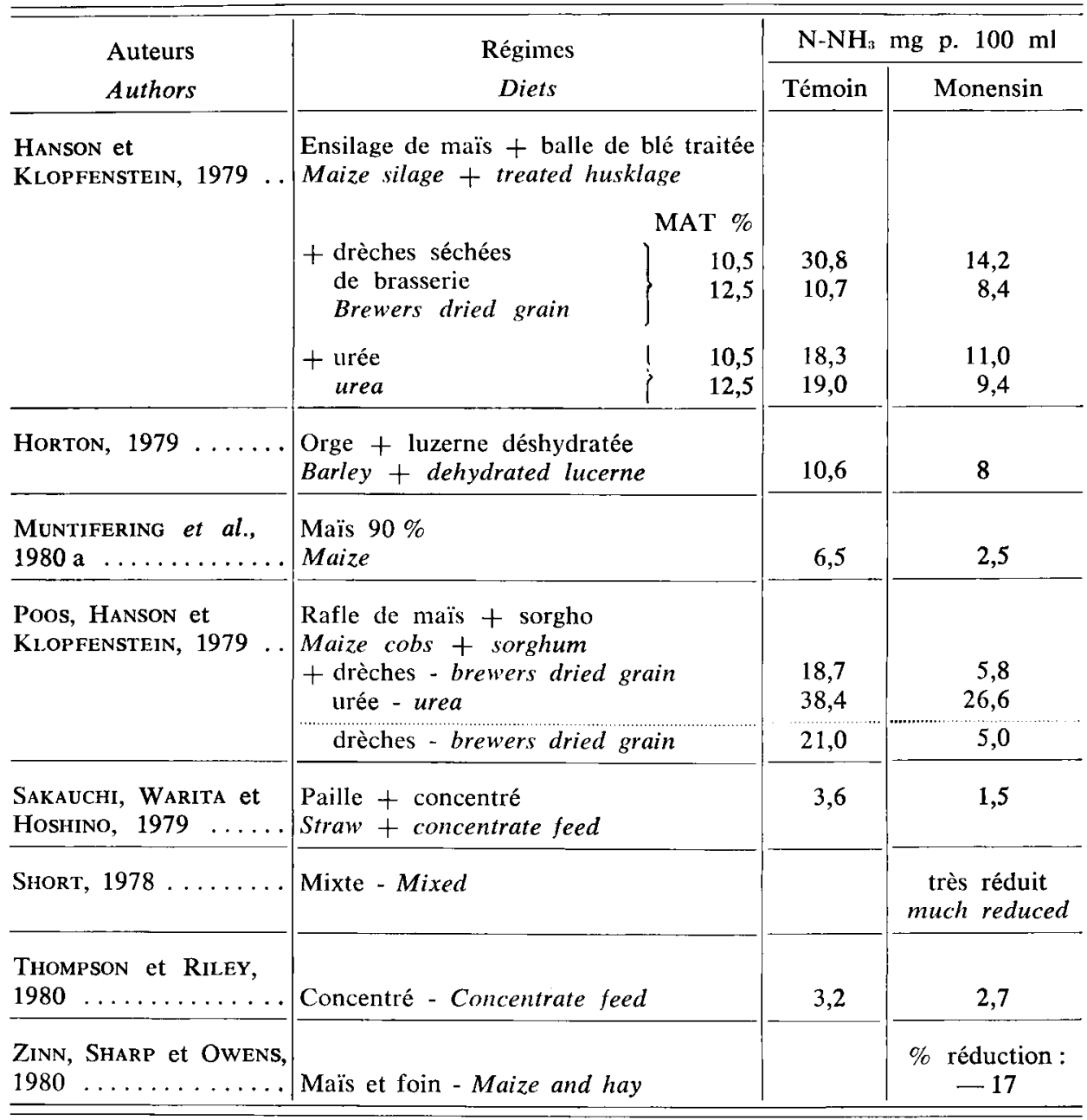

La quantité de protéines alimentaires retrouvée non dégradée à la sortie du rumen est accrue par le monensin dans l'expérience de Poos, Hanson \& Klopfenstein (1979) où un régime comportant 47 à 52 p. 100 de rafles de maïs plus 31 p. 100 de sorgho-grains a été complémenté par des drèches de brasserie ou de l'urée : l'azote d'origine alimentaire passe respectivement pour chacun des compléments de 70,8 à 97 et de 39,5 à $61,2 \mathrm{~g} / \mathrm{j}$. De même, la proportion de protéine qui n'est pas dégradée 
dans le rumen passe de 40 à 46 p. 100 dans l'expérience de Muntifering, Theurer \& NoON (1981).

L'abaissement des teneurs en $\mathrm{N}-\mathrm{NH}_{3}$ peut être, en partie, le reflet de cette protection des protéines alimentaires consécutive à l'ingestion de monensin. On peut aussi envisager un effet inhibiteur du monensin sur les uréases microbiennes ou les bactéries uréolytiques. En effet, il a été retrouvé davantage d'urée dans le rumen avec un régime purifié plus urée en présence de monensin (VAN NeVEL \& DemeYer, 1979) et, d'autre part, même avec des régimes contenant de l'urée les concentrations en $\mathrm{NH}_{3}$ sont fortement réduites (tableau 4). Cependant cet effet inhibiteur sur l'activité uréasique ne s'est pas manifesté in vitro, en culture continue (Wallace, Czerkawski, Breckenridge, 1981). Il est possible que les bactéries fixées à l'épithélium du rumen (CHENG \& Costerton, 1980), qui ont une structure de bactéries $\mathrm{G}^{+}$, soient particulièrement sensibles au monensin. Ces bactéries anaérobies facultatives sont uréolytiques et protéolytiques; leur inhibition pourrait réduire l'activité uréasique et protéolytique du contenu de rumen ainsi que l'ampleur du retour d'urée endogène du sang vers le rumen (CHENG \& Costerton, 1980); ceci expliquerait l'accroissement de l'urémie postprandiale observée par Poos, Hanson \& KLOPFENSTEIN (1979).

\section{- Protozoaires}

Plusieurs auteurs ont observé avec le monensin une réduction du nombre des protozoaires (Sakauchi, Warita \& Hoshino, 1979; Short, 1978 ; Poos, Hanson \& Klopfenstein, 1979). Dans l'expérience de ces derniers auteurs, la réduction est plus importante pour le régime complémenté en urée (68 p. 100) que le régime complémenté en drèches. JouanY \& SEnaud (1978) observent une réduction du volume occupé par les protozoaires. Il semble en effet que les grosses espèces soient les plus sensibles (Dennis, Nagaraja \& Bartley, 1981 b). Ainsi de même qu'in vitro en culture continue (Wallace, Czerkawski, Breckenridge, 1981), in vivo le monensin altérerait la composition de la population ciliée.

Une réduction du nombre de protozoaires peut aussi entraîner un abaissement des concentrations ammoniacales, les protozoaires ayant la faculté de dégrader les protéines alimentaires ou bactériennes. Cependant, plusieurs auteurs dont VAN Nevel \& Demeyer (1979) et Dinius, Simpson \& MARSH (1976), n'ont pas retrouvé cette influence du monensin sur le nombre des protozoaires.

\section{- Protéosynthèse microbienne}

La réduction de la protéosynthèse microbienne observée in vitro avec le monensin a été aussi observée dans quelques expériences in vivo. VAN NEvel \& DeMEYER (1979) observent une diminution des teneurs en $\mathbf{N}$ bactérien et en acide nucléique dans des contenus de rumen de mouton recevant des régimes purifiés avec urée. Poos, Hanson \& Klopfenstein (1979) observent une réduction de l'azote bactérien à la sortie du rumen chez les bouvillons, que le régime soit complémenté avec des drèches $(47,4$ contre $69,5 \mathrm{~g} \mathrm{~N} / \mathrm{j})$ ou avec de l'urée $(56,2$ contre $84,2 \mathrm{~g} \mathrm{~N} / \mathrm{j})$. Dans l'expérience de Muntifering, Theurer \& Noon (1981), la contribution de l'azote bactérien dans l'azote total du contenu de caillette est réduite par le monensin : 52 contre 58 p. 100 . 
Enfin, Allen \& Harrison (1979) montrent également une réduction de l'efficacité de la protéosynthèse avec le monensin chez le mouton : 20,2 contre $24,5 \mathrm{~g} \mathrm{~N} / \mathrm{kg}$ MO réellement digérée dans le rumen.

Outre les raisons évoquées précédemment pour la réduction in vitro de la protéosynthèse entraînée par le monensin, in vivo, l'abaissement du taux de renouvellement (TR) de la phase liquide du rumen consécutive à l'ingestion de cet additif pourrait être aussi un facteur important. Ainsi, les valeurs de TR observées avec ce produit sont nettement plus faibles qu'avec le témoin :

\begin{tabular}{|c|c|c|}
\hline & \multicolumn{2}{|c|}{ Taux de renouvellement $\%$ par heure } \\
\hline & Témoin & Monensin \\
\hline ALLEN et HARRISON, 1979 & 7,1 & 4,1 \\
\hline LEMENAGER et al., 1978 a & 6,5 & 4,5 \\
\hline
\end{tabular}

Or, nous avons vu précédemment le rôle prépondérant que l'on attribue à ce facteur dans l'efficacité de la protéosynthèse microbienne.

D'après les résultats des travaux effectués jusqu'à présent, il n'est pas possible de savoir si cet effet défavorable du monensin risque de continuer à se manifester après le premier mois de distribution. Quoi qu'il en soit, dans les régimes contenant de l'urée ( $>1$ p. 100 de l'aliment) cet additif peut avoir une action défavorable : Poos, Hanson \& KLOPfEnstein (1979) observent chez les agneaux une réduction du bilan azoté $(1,7$ contre $3,6 \mathrm{~g} \mathrm{~N} / \mathrm{j})$ avec la distribution de monensin après 10 jours d'adaptation, tandis que HANson \& KLOPFENSTEIN (1979) observent au cours d'une expérience de 127 jours une légère réduction de l'efficacité alimentaire chez le taurillon qui recevait des régimes contenant 1,3 ou 2,1 p. 100 d'urée.

\section{Conclusion}

Les antibiotiques ionophores peuvent orienter favorablement la digestion dans le rumen en élevant la proportion d'acide propionique dans les produits terminaux de la fermentation des glucides, en réduisant sensiblement la formation de $\mathrm{CH}_{4}$, en protégeant une partie des protéines alimentaires contre la désamination microbienne et dans certains cas en réduisant le nombre de protozoaires.

Après quelques semaines d'adaptation au monensin, il ne semble pas que l'activité cellulolytique risque d'être réduite, bien que les résultats de Oltuen, Dinius \& Goring (1977) soit particulièrement négatifs. Il apparaît plutôt, en général, que le monensin en ralentissant le transit des particules (ou en réduisant les quantités ingérées) permette aux matières cellulosiques de rester plus longtemps au contact des bactéries assurant ainsi une digestion plus poussée compensant l'éventuelle disparition de certaines espèces bactériennes cellulolytiques.

Dans des régimes normalement pourvus en protéines végétales, la protection de ces dernières, assurée par le monensin, doit compenser son effet inhibiteur sur la synthèse de protéine microbienne. Ainsi, la quantité de $\mathbf{N}$ non $\mathrm{NH}_{3}$ ou d'acides 
aminés arrivant au niveau intestinal peut rester inchangée (Poos, Hanson \& KLOPFENSTEIN, 1979 ; ZinN, Sharp \& OWENS, 1980).

Dans des régimes riches en azote non protéique (1 p. 100 d'urée) et pauvres en protéine végétale, la réduction de la protéosynthèse microbienne peut avoir des répercussions défavorables sur le métabolisme azoté de l'hôte. De plus, dans des régimes pauvres en azote, le monensin en réduisant l'activité des bactéries uréolytiques risquerait de nuire à l'efficacité du recyclage de l'azote entraînant une carence en $\mathrm{NH}_{3}$ pour la flore.

Parmi les modes d'actions possibles de ces additifs, ceux suggérés récemment par les bactériologistes (Chen \& Wolin, 1979; Dennis, Nagaraja \& Bartley, 1981 a) sont particulièrement séduisants. Cependant, un effet du monensin sur les échanges d'ions à travers la paroi de l'épithélium du rumen n'est pas non plus à exclure et pourrait aussi expliquer, pour une part, l'effet de ce produit sur le transit ou le volume de contenu. Une augmentation des teneurs en potassium du contenu de rumen de 22 p. 100 observée par LEMENAGER, OWens \& Totusek $(1978 \mathrm{~b})$ en est le témoignage. Cet aspect méritera d'être approfondi dans l'avenir, car des modifications dans les facteurs physicochimiques de l'environnement microbien peuvent influencer considérablement le métabolisme de la micropopulation.

\section{Antibiotiques classiques}

De nombreux antibiotiques ont été utilisés pour tenter d'orienter favorablement les fermentations dans le rumen. Si leurs effets in vitro sont parfois positifs, généralement, in vivo, ou bien ils réduisent la production d'acides gras volatils ou bien la flore s'adapte rapidement (CHAlupA, 1980). Cependant, cela ne semble pas être le cas pour l'avoparcine, antibiotique produit par une souche de Streptomyces candidus qui agit contre certaines bactéries Gram ${ }^{+}$. L'avoparcine, comme les antibiotiques ionophores, élèverait le pourcentage de propionate dans les acides gras volatils ; cela a été montré après 100 jours de traitement chez des bouvillons recevant $66,0 \mathrm{mg} / \mathrm{kg}$ d'avoparcine dans l'aliment (JoHNSON et al., 1979). En règle générale, l'avoparcine réduit la quantité d'aliment ingéré par unité de gain de poids, son effet serait même supérieur à celui du monensin (JoHnSON et al., 1979 ; DYER et al., 1980). Par contre, l'influence de cet antibiotique sur la croissance des bactéries du rumen ou leur activité cellulolytique n'est apparemment pas encore connue.

Parmi les antibiotiques peptidiques contenant du soufre, la thiopeptine qui inhibe la croissance de Streptococcus bovis in vitro réduit considérablement la formation d'acide lactique in vivo lors d'un passage brutal à un régime de céréales micronisées (Muir et al., 1981). Le pH se maintient alors dans une zone favorable à la formation d'acides gras volatils (Muir et al., 1981). Cet antibiotique devrait pouvoir éviter l'acidose lactique courante dans les passages rapides d'un régime de fourrage à un régime de céréales.

\section{Inhibiteurs de la méthanogénèse}

Dans un premier temps, on a proposé des produits accepteurs d'électrons qui devaient entrer en compétition avec la formation de méthane. Effectivement, certains 
de ces agents (sulfate, nitrate...) inhibaient in vitro la production de $\mathrm{CH}_{4}$. Cependant, l'effet de ces substances n'étant pas suffisamment sélectif, leur application in vivo n'a pas été retenue.

Les analogues halogénés du méthane sont de puissants inhibiteurs de la méthanogénèse, mais sont trop volatils pour être utilisés in vivo. Plusieurs produits halogénés (alcools, aldéhydes, esters polyhalogénés) ont une action anti-méthanogène. On utilise le plus souvent l'amicloral (hémiacétal d'hydrate de chloral et d'amidon) ou l'hydrate de chloral.

L'un des produits de leur dégradation dans le rumen, le chloroforme, inhibe fortement la formation de $\mathrm{CH}_{4}$. Ces produits exercent un effet toxique sélectif sur les bactéries méthanogènes; ils auraient une action irréversible avec la vitamine $B_{12}$ réduite et empêcheraient le transfert du groupement méthyle dépendant du coenzyme $B_{12}$. Toutefois, on ne détecte pas toujours de coenzyme $B_{12}$ dans les bactéries méthanogènes (VAN NeVEL \& DeMEYER, 1976).

L'inhibition de formation de méthane s'accompagne généralement d'une élévation des proportions de propionate, butyrate et parfois lactate qui jouent le rôle d'accepteurs d'hydrogène, mais ce dernier peut aussi s'accumuler (DEMEYER \& VAN NEvEL, 1975) lorsqu'il est en excès.

Nous donnons un exemple extrait de Chalupa (1980) de l'effet de l'amicloral sur les fermentations glucidiques en culture continue :

\begin{tabular}{|c|c|c|}
\hline mmoles/j & Témoin & $\begin{array}{c}\text { Amicloral } \\
10 \mathrm{ppm} \mathrm{du} \mathrm{milieu}\end{array}$ \\
\hline Méthane. & 15,2 & 4,8 \\
\hline Hydrogènc & 0,7 & 3,4 \\
\hline Acétate $\ldots \ldots \ldots \ldots$ & 46,7 & 40,8 \\
\hline Propionate $\ldots \ldots \ldots \ldots \ldots \ldots \ldots$ & 11,4 & 15,4 \\
\hline Butyrate $\ldots \ldots \ldots \ldots \ldots \ldots \ldots \ldots$ & 4,5 & 6,6 \\
\hline
\end{tabular}

Dans des essais comparatifs en culture discontinue portant sur le monensin et l'amicloral Chalupa, CorbetT \& Brethour (1980) ont observé que ce dernier inhibait davantage la méthanogénèse et produisait plus de butyrate et d'hydrogène que le monensin. Les deux produits réduisaient d'environ 50 p. 100 la disparition des acides aminés libres ajoutés dans le milieu.

En culture continue, Stanier \& Davies (1981) ont observé également que le produit halogéné testé (ICI 111075) inhibait davantage la production de méthane et produisait davantage d'hydrogène dans le milieu que le monensin.

Cependant, les inhibiteurs de $\mathrm{CH}_{4}$ peuvent aussi avoir un effet défavorable sur l'efficacité de la protéosynthèse microbienne in vitro. Les résultats de VAN NeVEL \& Demeyer (1981) obtenus avec des suspensions lavées de bactéries montrent une réduction de l'efficacité de la protéosynthèse de 14 à 25 p. 100 selon la dose d'hydrate de chloral et ceux de Stanier \& Davies (1981) en culture continue une réduction de 10 p. 100 avec le produit ICI 111075. 
In vivo, on retrouve l'effet inhibiteur des produits sur la production de $\mathrm{CH}_{4}$, mais l'accroissement du taux de propionate ou les effets sur les performances des animaux ne sont pas toujours significatifs. Les effets négatifs peuvent s'expliquer par une adaptation de la flore aux produits (CHALUPA, 1980), par une accumulation importante d'hydrogène dans le milieu (VAN Nevel \& Demeyer, 1976) ou d'accepteurs d'hydrogène ayant un effet plus ou moins toxique, ou bien par l'induction d'une carence en vitamine $\mathbf{B}_{12}$.

Par ailleurs, ces produits peuvent inhiber partiellement la protéolyse dans le rumen, comme en témoignent des teneurs plus faibles en ammoniac du rumen, ce qui a parfois été une des causes de l'amélioration du bilan azoté (Chalupa, 1977).

L'efficacité de ces produits sur l'utilisation de l'aliment dépend également de la nature du régime et des quantités ingérées. Elle s'abaisse généralement lorsque la teneur en concentré du régime s'élève entraînant ainsi une moindre production de méthane, ou lorsqu'une partie notable de l'aliment n'est pas fermentée au niveau du rumen (ingestion en quantité importante de particules fines). D'après VAN NEVEL \& Demeyer (1976), on ne peut s'attendre à des effets significatifs des antiméthanogènes sur la croissance qu'avec des rations classiques comportant des fourrages grossiers.

\section{Inhibiteurs de désamination}

Des composés diphényliodonium se sont montrés efficaces pour inhiber la dégradation des acides aminés par les microorganismes du rumen (Chalupa, Chow \& Parish, 1976 ; Chalupa, 1977). Ils conduisent à une accumulation d'acides aminés libres dans le liquide de rumen comme le montrent les résultats de Broderick \& BALTHRop (1979). Ces derniers auteurs observent, de plus, une accumulation d'alanine dans le milieu en présence de chlorure de diphényliodonium. L'alanine, nous l'avons vu, joue un rôle d'intermédiaire dans la transformation des autres acides aminés. Le diphényliodonium inhiberait la dégradation de l'alanine en $\mathrm{NH}_{3}$, acétate et $\mathrm{CO}_{2}$, sans doute en empêchant la régénération du NADH. Cependant, à partir de $0,05 \mathrm{mM}$ d'inhibiteur dans le milieu, l'incorporation de $\mathrm{NH}_{3}$ dans les bactéries est réduite, ainsi que la protéosynthèse comme l'a montré CHALUPA (1977). D'après TAMminga $(1979 \mathrm{~b})$, la glutamate deshydrogénase (NAD+ dépendante) pourrait être moins activée. Or, il s'agit de l'enzyme-clef de l'utilisation du $\mathrm{NH}_{3}$ par les bactéries.

Les composés diphényliodonium pourraient orienter favorablement les fermentations glucidiques; Chalupa (1980) observe une réduction de la production de $\mathrm{CH}_{4}$ de 24 p. 100 , une baisse de l'acétate et une augmentation du propionate, ce qui élèverait le rendement de fermentation.

In vivo, Horton (1980), montre que, distribuée à raison de 25 ppm dans la ration de bouvillons, le composé diphényliodonium n'a pas eu d'effet significatif sur la composition des $\mathrm{AGV}$, mais a accru de 10 points la digestibilité des matières cellulosiques; les teneurs en $\mathrm{NH}_{3}$ ont été abaissées de 60 p. $100(7,2$ contre $16,3 \mathrm{mg} \mathrm{N} / 100 \mathrm{ml}$ ). Dans une autre expérience, HorTon (1979) a montré une accumulation d'acides aminés libres dans le contenu de rumen (de 3 fois supérieure à celle du témoin), ce qui indique clairement une inhibition de la désamination. Chalupa (1980) a montré que ces produits augmentaient la rétention azotée et l'utilisation de l'azote absorbé. Pour un gain de poids égal, l'inhibiteur de désaminase permet d'abaisser la teneur en matière azotée de la ration de 14,4 à 11,1 p. 100 
chez le jeune taurillon. Cependant, des études supplémentaires doivent être entreprises pour démontrer que la protéosynthèse bactérienne ne risque pas d'être réduite, notamment avec des régimes contenant de l'azote non protéique et que la digestion de la cellulose se poursuit normalement.

\section{IV. - Conclusion}

Nous avons évoqué l'action des principaux additifs qui permettent actuellement d'orienter la digestion microbienne dans le rumen, afin d'accroître les quantités d'énergie et d'acides aminés disponibles pour l'animal à partir d'un aliment donné. Nous avons vu que leur action ne s'exerçait généralement pas sélectivement sur une voie métabolique particulière, mais qu'ils pouvaient entraîner des effets secondaires parfois favorables, mais aussi parfois néfastes à l'hôte (inhibition de la protéosynthèse ou de la cellulolyse). La recherche de produits agissant plus sélectivement sur les pertes d'énergie et d'azote est certainement souhaitable. En ce qui concerne les antibiotiques ionophores, les recherches en cours sur le lasalocide apporteront peut-être de nouvelles informations dans ce domaine. Par ailleurs, l'association de deux agents à actions différentes pourra éventuellement éviter des effets secondaires néfastes. Slyter (1979) a montré que lassociation monensin + inhibiteur de méthanogénèse permettait d'annuler l'effet inhibiteur de ce dernier sur la dégradation des glucides pariétaux. Les essais effectués jusqu'ici sur ces associations sont trop partiels pour qu'il puisse en être tiré des applications pratiques.

La recherche d'agents agissant à d'autres niveaux du métabolisme du rumen reste nécessaire.

Avec des régimes pauvres en protéines végétales, l'inhibition de la croissance des protozoaires peut, en élevant la quantité de protéines à la sortie du rumen, améliorer l'efficacité alimentaire (CHALupa, 1980). L'emploi d'agents défaunants (comme les détergents non ionisés) devra donc faire l'objet de recherches approfondies.

Les possibilités de contrôle des caractéristiques physicochimiques de l'environnement microbien, $\mathrm{pH}$, osmolarité, vitesse de renouvellement du contenu, devront aussi être expérimentées en agissant sur la salivation, la motilité, les échanges à travers la paroi du rumen.

Par ailleurs, nous n'avons rencontré, dans notre étude bibliographique, que fort peu de données sur des produits susceptibles de stimuler la dégradation des glucides des parois végétales. Dans ce domaine, très récemment, un fongicide utilisé aux Etats-Unis pour la conservation du maïs-grain, le «Captan » s'est révélé être efficace in vitro et in vivo (Theuninck, Goodrich \& MeISKe, 1981). L'amélioration de i'utilisation des fourrages pauvres ou des sous-produits riches en matière cellulosique étant un problème d'actualité, l'étude de ce genre de produit se doit d'être poursuivie activement.

Accepté pour publication en mars 1982.

\section{Remerciements}

L'auteur remercie Geneviève Hannequart pour son aide au cours des recherches bibliographiques. 


\section{Summary}

\section{Manipulation of rumen metabolism with additives}

In order to optimize the efficiency of feed utilization in ruminants research has been directed towards chemicals which might lead to a reduction of energetic losses (particularly $\mathrm{CH}_{4}$ ) and of nitrogen losses (as $\mathrm{NH}_{3}$ ) in the rumen, without affecting the positive effect of microbial digestion : fibre degradation and microbial protein synthesis from NPN. Several types of additives have been suggested. Their advantageous or detrimental effects are discussed in this paper.

In order to understand how rumen fermentation could be manipulated by the use of additives some of the recent concepts developed on carbohydrates and nitrogen metabolism in the rumen are described. Attention is paid to the biochemistry of carbohydrate fermentation (Fig. 1, table 1) and the interactions between various types of bacteria in the formation of propionate, acetate and methane. The principal steps and organisms involved in protein degradation and some of the major factors affecting the synthesis of microbial synthesis (energy and nitrogen availability, the turnover rate of the rumen liquid phase) are dealt with.

Ionophore antibiotics (Fig. 2) such as monensin and lasalocid stimulate propionate production (increase of molar percentage of propionate) either in vitro (Table 3 ), whatever the type of culture, or in vivo, with most of the diets. As a result, the molar percentages of both acetate and butyrate as well as $\mathrm{CH}_{4}$ production are generally reduced. Furthermore they protect aminoacids as shown by the decrease in rumen $\mathbf{N H}_{3}$ levels (Table 4) and sometimes by accumulation of amino-nitrogen. However, when animals have not been adapted to the drugs, cellulose digestion as well as microbial protein synthesis are often reduced. With adapted animals, these detrimental effects and especially the firt one, often disappear. When observed in vivo, the decrease of bacterial protein synthesis can often be related to a decreased turnover rate of the ruminal liquid phase.

The mechanisms by which ionophores alter rumen fermentation would primarily be an alteration in the microbial community (Table 2) : formate and $\mathrm{H}_{2}$ producing bacteria are very sensitive to these drugs, whereas succinate producers and lactate fermenters are resistant; a propionate producing microbial community is therefore selected. Modifications in ion exchanges through the rumen wall, which may explain the decrease in turnover rate of the liquid phase might also be involved. In practice, monensin could be detrimental to nitrogen metabolism in the animals when diets are high in NPN $(>1$ p. 100 of urea) and low in protein.

The halogenated methane analogues are potent inhibitors of methanogenesis and sometimes decrease protein degradation. However, they may inhibit microbial protein synthesis. In vivo, animal performances are not always improved because of an adaptation of the flora, or because the accumulation of hydrogen or hydrogen acceptors is more or less toxic.

Diphenyliodonium chemicals are very efficient inhibitors of aminoacid degradation in the rumen. In addition they would favourably adjust carbohydrate fermentation. More studies are necessary to make sure that they have no detrimental influences upon microbial growth and fibre digestibility.

It is concluded that more research should be directed towards chemical likely to increase crude fibre digestion in the rumen.

\section{Références bibliographiques}

Allen J.D., Harrison D.G., 1979. The effect of the dietary addition of monensin upon digestion in the stomachs of sheep. Proc. Nutr. Soc., 38, 32A.

Bergen W.G., Yokoyama M.T., 1977. Productive limits to rumen fermentation. J. anim. Sci., 45, 573-584. 
Bartley E.E., Herod E.L., Bechtle R.M., Sapienza D.A., Brent B.E., 1979. Effect of monensin or lasalocid, with and without niacin or amicloral, on rumen fermentation and feed efficiency. J. anim. Sci., 49, 1066-1075.

Broderick G.A.. Balthrop J.E., 1979. Chemical inhibition of amino acid deamination by ruminal microbes in vitro. J. anim. Sci., 49, 1101-1111.

BRYANT P.M., 1973. Nutritional requirements of the predominant rumen cellulolytic bacteria. Fed. Proc., 32, 1809-1813.

Chalupa W., 1977. Manipulating rumen fermentation. J. anim. Sci., 45, 585-599.

Chalupa W., 1978. Digestion and absorption of nitrogenous compounds in ruminants. In : 3rd World Congress Anim. Feed. Madrid, 211-230.

Chalupa W., 1980. Chemical control of rumen microbial metabolism. In : Digestive physiology and metabolism in ruminants. Proc. 5th Intern. Symp. Ruminant Physiol., Clermont-Ferrand. Ed. by Y. Ruckebusch and P. Thivend (M.T.P. Press Ltd, Lancaster), 325-347.

Chalupa W., Chow A.W., Parish R.C., 1976. Chemical control of amino acid degradation by rumen microbes. Fed. Proc., 35, 258.

Chalupa W., Corbett W., Brethour J.R., 1980. Effects of monensin and amicloral on rumen fermentation. J. anim. Sci., 51, 170-179.

Chen M.. Wolin M.J., 1979. Effect of monensin and lasalocid-sodium on the growth of methanogenic and rumen saccharolytic bacteria. Appl. Environ. Microbiol., 38, 72-77.

Cheng K.J., Costerton J.W., 1980. Adherent rumen bacteria - Their role in the digestion of plant material, urea and epithelial cells. In : Digestive physiology and metabolism in ruminants. Proc. 5th Intern. Symp. Ruminant Physiol., Clermont-Ferrand. Ed. by Y. Ruckebusch and P. Thivend (M.T.P. Press Ltd, Lancaster), 227-250.

Demeyer D.I.. 1981. Rumen microbes and digestion of plant cell walls. Agric. Environ., 6. $295-337$.

Demeyer D.I.. Van Nevel C.J., 1975. Methanogenesis, an integrated part of carbohydrate fermentation, and its control. In : Digestion and metabolism in the ruminant. Proc. 4th Intern. Symp. Ruminant Physiol., Sydney, Australia. Ed. by I.W. MCDonald and A.C.I. WARNER, 366-382.

Demeyer D.I.. Van Nevel C.J., 1980. Nitrogen exchanges in the rumen. Proc. Nutr. Soc., 39, 89-95.

Dennis S.M., Nagaraja T.G., Bartley E.E., 1981 a. Effects of lasalocid or monensin on lactate-producing or-using rumen bacteria. J. anim. Sci., 52, 418-426.

Dennis S.M., Nagaraja T.G., Bartley E.E., 1981 b. The effects of lasalocid, monensin and thiopeptin on rumen protozoa. A.D.S.A. annual meeting. Abstr. p. 153, supp. 1.

Dinius D.A., Simpson M.E., Marsh P.B., 1976. Effect of monensin fed with forage on digestion and the ruminal ecosystem of steers. J. anim. Sci., 42, 229-234.

Durand M., Kawashima R., 1980. Influence of minerals in rumen microbial digestion. In : Digestive physiology and metabolism in ruminants. Proc. 5th Intern. Symp. Ruminant Physiol., Clermont-Ferrand. Ed. by Y. Ruckebusch and P. Thivend (M.T.P. Press Ltd, Lancaster), 375-408.

Dyer I.A., Koes R.M., Herlugson M.L., Bola Ojikutu L., Preston R.L., Zimmer P., DELAY R., 1980. Effect of ovoparcin and monensin on performance of finishing heilers. J. anim. Sci., 51, 843-846.

Hanson T.L., Klopfenstein T.J., 1979. Monensin, protein source and protein levels for growing steers. J. anim. Sci., 48, 474-479.

HARRIson D.G., MCAllan A.B., 1980. Factors affecting microbial growth yields in the reticulo-rumen. In : Digestive physiology and metabolism in ruminants. Proc. 5th Intern. Symp. Ruminant Physiol., Clermont-Ferrand. Ed. by Y. Ruckebusch and P. Thivend (M.T.P. Press Ltd, Lancaster), 205-226.

Herod E.L., Bartley E.E., Davidovich A., Bechtle R.M., Sapienza D.A., Brent B.E., 1979. Effect of adaptation to monensin or lasalocid on rumen fermentation in vitro and the effect of these drugs on heifer growth and feed efficiency. J. anim. Sci., 49, Suppl. 1, 374 (Abstr.). 
Horn G.W., Mader T.L., Armbruster S.L., Frahm R.R., 1981. Effect of monensin on ruminal fermentation, forage intake and weight gains of wheat pasture stocker cattle. J. anim. Sci., 52, 447-454.

Horton G.M.J., 1979. Ruminal effects of a deaminase inhibitor and monensin. Ann. Rech. Vét., 10, 335-337.

Horton G.M.J., 1980. Use of feed additives to reduce ruminal methane production and deaminase activity in steers. J. anim. Sci., 50, 1160-1164.

Horton G.M.J., Nicholson H.H., 1980. Rumen metabolism and feedlot responses by steers fed tylosin and monensin. Can. J. anim. Sci., 60, 919-924.

I.N.R.A., 1978. Alimentation des Ruminants. Ed. I.N.R.A. publications (route de SaintCyr), 78000 Versailles, $600 \mathrm{pp}$.

Johson R.J., Herlugson M.L., Bola Ojikutu L., Cordova G., Dyer 1.A., Zimmer P., Delay R., 1979. Effect of avoparcin and monensin on feed lot performance of beef cattle. J. anim. Sci., 48, 1138-1342.

Jouany J.P., Senaud J., 1978. Utilisation du monensin dans la ration des ruminants. II. Effets sur les fermentations et la population microbienne du rumen. Ann. Zootech., 27, 61-74.

Lemenager R.P., OWens F.N., Shockey B.J., Lusby K.S., Totusek R.. 1978 a. Monensin effects on rumen turnover rate, twenty-four hour VFA pattern, nitrogen components and cellulose disappearance. J. anim. Sci., 47, 255-261.

Lemenager R.P., Owens F.N., Totusek R., 1978 b. Monensin and extruded urea-grain for range beef cows. J. anim. Sci., 47, 262-269.

LyLE R.R., Johnson R.R., Backus W.R., 1981. Ruminal characteristics as affected by monensin, type of protein supplement and proportions of whole wheat and corn in forage-free diets fed to finishing steers. J. anim. Sci., 53, 1377-1382.

McClure W.H., Fontenot J.P., WebB K.E., Lucas D.M., 1980. Feedlot performance of cattle fed different salinomycin levels. J. anim. Sci., 51, Suppl. 1, 380 (Abstr.).

Muir L.A., Rickes E.L., Duquette P.F., Smith G.E., 1981. Prevention of induced lactic acidosis in cattle by thiopeptin. J. anim. Sci., 52, 635-643.

Muntifering R.B., Theurer C.B., Swingle R.S., Hale W.H., 1980. Effects of monensin on nitrogen utilization and digestibility of concentrate diets by steers. J. anim. Sci., 50, 930-936.

Muntifering R.B., Theurer C.B., Noon T.H., 1981. Effects of monensin on site and extent of whole corn digestion and bacterial protein synthesis in beef steers. J. anim. Sci., 53, 1565-1573.

Nagaraja T.G., Avery T.B., Bartley E.E., Galitżer S.J., Dayton A.D., 1981. Prevention of lactic acidosis in cattle by lasalocid or monensin. J. anim. Sci., 53, 206-216.

Oltjen R.R., Dinius D.A., Gering H.K., 1977. Performance of steers fed crop residues. supplemented with non protein nitrogen, minerals, protein and monensin. J. anim. Sci., 45, 1442-1452.

OrsKov E.R., 1980. Adherent rumen bacteria - Their role in the digestion of plant material, urea and epithelial cells. In : Digestive physiology and metabolism in ruminants. Proc. 5th Intern. Symp. Ruminant Physiol., Clermont-Ferrand. Ed. by Y. Ruckeibusch and P. Thivend (M.T.P. Press Ltd, Lancaster), 227-250.

Parisini P., Rizzi L., Scipioni R., 1979. Esperienze sull'impiego di "Monensin sodium» nella produzione del vitellone. Riv. Zootec. Vet., $\mathrm{n}^{\circ} 1,19-25$.

Poos M.I., Hanson T.L., Klopfenstein T.J., 1979. Monensin effects on diet digestibility, ruminal protein bypass and microbial protein synthesis. J. anim. Sci., 48, 1516-1524.

Prange R.W., Davis C.L., Clark J.H., 1978. Propionate production in the rumen of holstein steers fed either a control or monensin supplemented diet. J. anim. Sci., 46, 1120-1124.

Prins R.A., Clarke R.T.J., 1980. Microbial ecology of the rumen. In : Digestive physio$\log y$ and metabolism in ruminants. Proc. 5th Intern. Symp. Ruminant Physiol., Clermont-Ferrand. Ed. by Y. Ruckebusch and P. Thivend (M.T.P. Press Ltd, Lancaster), 179-204. 
Richardson A.P., Raun A.P., Potter E.L., Cooley C.O., Rath Matcher R.P., RichardSON L.F., 1976. Effect of monensin on rumen fermentation in vitro and in vivo. J. anim. Sci., 43, 657-669.

Sakauchi R., Warita M., Hoshino S., 1979. Effect of monensin on ruminal VFA and ammonia levels and microbes of finishing feedlot cattle. Jpn J. Zootechn. Sci., 50, 369-374.

SchwartZ H.M., Gilchrist F.M.C., 1975. Microbial interactions with the diet and the host animal. In : Digestion and metabolism in the ruminant. Proc. 4th Intern. Symp. Ruminant Physiol., Sydney Australia. Ed. by I.W. MCDonald and A.C.I. Warner, 165-179.

Shell L., Hale W.H., Theurer C.B., 1979. Monensin and volatile fatty acid (VFA) production in fistulated steers. J. anim. Sci., 49, Suppl. 1, 404 (Abstr.).

SHORT D.E., 1978. Rumen fermentation and nitrogen metabolism as affected by monensin. Diss. Abstr. Int., 39 (5), p. 2029-B.

SIMPSON M.E., 1978. Effects of certain antibiotics on in vitro cellulose digestibility and volatile fatty acid (VFA) production by ruminal microorganisms. J. anim. Sci., 47, Suppl. 1, 439 (Abstr.).

SLYTER L.L., 1979. Monensin and dichloroacetamide influences on methane and volatile fatty acid production by rumen bacteria in vitro. Appl. environ. Microbiol., 37, 283-288.

Stanier G., Davies A., 1981. Effects of the antibiotic monensin and an inhibitor of methanogenesis on in vitro continuous rumen fermentations. Br. J. Nutr., 45, 567-578.

SuTton J.D., 1980. Digestion and end-product formation in the rumen from production rations. In : Digestive physiology and metabolism in ruminants. Proc. 5th Intern. Symp. Ruminant Physiol., Clermont-Ferrand. Ed. by Y. RuCKebusch and P. THivend (M.T.P. Press Ltd, Lancaster), 271-290.

Tamminga S., 1979 a. Relation between different carbohydrates and microbial synthesis of protein. Kiel group seminar. Uppsala 13-14 june 1979, Rep. n" 130.

TAmminga S., 1979 b. Protein degradation in the forestomachs of ruminants. J. anim. Sci., 49, $1615-1630$.

TEMPEST D.W., 1969. Quantitative relationships between inorganic cations and anionic polymers in growing bacteria. In : Microbial growth. 9th Symp. Soc. Gen. Microbiol. London, Vol. 19. Ed. by P.M. Meadow and S.J. PirT. Camb. Univ. Press, New York, 87-111.

Theuninck D.H., Goodrich R.D., Meiske J.C., 1981. Influence of captan on in vitro and in vivo digestibility of forage. J. anim. Sci., 52, 377-381.

Thompson W.R., RILeY J.G., 1980. Protein levels with and without monensin for finishing steers. J. anim. Sci., 50, 563-571.

Thonney M.L., Heide E.K., Duhaime D.J., Hand R.J., Perosio D.J., 1981. Growth, feed efficiency and metabolite concentrations of cattle fed high forage diets with lasalocid or monensin supplements. J. anim. Sci., 52, 427-433.

ThORNTON J.H., OWENS F.N., 1981. Monensin supplementation and in vitro methane production by steers. J. anim. Sci., 52, 628-634.

Van MaAnen R.W., Herbein J.H., McGilliard A.D., Young J.W., 1978. Effects of monensin on in vivo rumen propionate production and blood glucose kinetics in cattle. J. Nutr., 108, 1002-1007.

Van Nevel C.J., Demeyer D.I., 1976. Inhibition de la production de méthane dans le rumen : aperçu de la littérature. Revue de l'Agriculture, 2, mars-avril, 431-452.

Van Nevel C.J., Demeyer D.I., 1977. Effect of monensin on rumen metabolism in vitro. Appl. Environ. Microbiol., 34, 251-257.

Van Nevel C.J., Demeyer D.I., 1979. Effect of monensin on some rumen fermentation parameters. Ann. Rech. Vét., 10, 338-340.

Van Nevel C.J., Demeyer D.I., 1981. Effect of methane inhibitors on the metabolism of rumen microbes in vitro. Arch. Tierernähr., 31, 141-151. 
Wallace R.J., Czerkawski J.W., Breckenridge G., 1981. Effect of monensin on the fermentation of basal rations in the Rumen Simulation Technique (Rusitec). Br. J. Nutr., 46, 131-148.

Weeb K.E., Fontenot J.P., LuCas D.M., 1980. Metabolism studies in steers fed different levels of salinomycin. J. anim. Sci., 51, Suppl. 1, 407 (Abstr.).

Westley J.W., 1977. Polyether antibiotics : versatile carboxylic acid ionophores produced by Streptomyces. Adv. Appl. Microbiol, 22, 177-223.

Whetstone H.D., Davis C.L., Bryant M.P., 1981. Effect of monensin on breakdown of protein by ruminal microorganisms in vitro. J. anim. Sci., 53, 803-809.

Wol.IN M.J., 1975. Interactions between the bacterial species of the rumen. In : Digestion and metabolism in the ruminant. Proc. 4th Intern. Symp. Ruminant Physiol., Sydney, Australia. Ed. by I.W. MCDONALd and A.C.I. WARNER, 134-148.

ZinN R.A., SharP W., OWENS F.N., 1980. Influence of monensin on ruminal nitrogen distribution and site of direstion. J. anim. Sci., 51, Suppl. 1, 413 (Abstr.). 